\title{
Contributions of Micro, Small and Medium Enterprises (MSMEs) to Income Generation, Employment and GDP: Case Study Ethiopia
}

\author{
Hailai Abera Weldeslassie ${ }^{1}$, Claire Vermaack ${ }^{1}$, Kibrom Gebrekirstos ${ }^{2}$, Luback Minwuyelet ${ }^{3}$, Mahlet Tsegay ${ }^{3}$, \\ Negasi Hagos Tekola ${ }^{3} \&$ Yemane Gidey ${ }^{3}$ \\ ${ }^{1}$ Department of Economics, School of Accounting, Economics and Finance, College of Law and Management \\ Studies, University of KwaZulu-Natal, Durban, South Africa \\ ${ }^{2}$ Department of Economics, College of Business and Economics, Adigrat University, Ethiopia \\ ${ }^{3}$ College of Business and Economics, and College of Social Science and Languages, Aksum University, Ethiopia \\ Correspondence: Hailai Abera Weldeslassie, Department of Economics, School of Accounting, Economics and \\ Finance, College of Law and Management Studies, University of KwaZulu-Natal, Durban, South Africa. E-mail: \\ addeyagoza@yahoo.com
}

Received: March 2, 2019

doi:10.5539/jsd.v12n3p46
Accepted: April 10, $2019 \quad$ Online Published: May 30, 2019

URL: https://doi.org/10.5539/jsd.v12n3p46

\begin{abstract}
The pillar goals of this research are to review the conditions of MSMEs, their contribution to employment creation, income generation, poverty alleviation, contributions to the local, regional and national GDP, stimulating entrepreneurial climate and the challenges and opportunities in the design, implementations, marketing opportunities, linkages, financial sources, dynamics, survival and policy landscape. To achieve the presented purposes, we collected primary and secondary data through a survey, focus group discussions and documents reviews. We used qualitative and quantitative approaches to analyse the collected data using various statistical programs.

We used descriptive and econometric statistical analysis to process the data, obtain the relevant estimation results and fully discuss the purposes under the study. We firmly maintain that the systems we presented, and the methods applied enabled us to tackle the aims of the study. MSMEs in Ethiopian are the chief sources of job, income, significantly contribute to the local, regional and national GDP and key policies to eliminate poverty.

In the log-linear regression, we found that MSMEs initial capital, BDS, access to credit facility are the key determinants of MSMEs performance. Majority of the MSMEs produce for local and regional markets; few for national markets and none for international markets. Besides, we found that sex of MSMEs owner/manager, BDS, access to credit and capital size strongly determine the survival of MSMEs.

Based on this study, the major obstacles of MSMEs in Ethiopia are the question of sustainability, lack of credit, weak market linkage, insufficient training, weak human resources development schemes, dependency on government and spoon-feeding mentality, oscillations in government policies, price variations, weak links and poor market and product development strategies.

Acronyms: CSA-Central Statistical Agency, EFFORT-Endowment Fund for the Rehabilitation of Tigray, EUEuropean Union, FGT- Foster Greer Thorbeck, GDP- Gross Domestic Product, GTP- Growth and Transformation Plan, HICE -Household, Income and Consumption Expenditure, ILO - International Labor Office, MSEs-Micro and Small Enterprises, MSMEs-Micro Small and Medium Enterprises, OECD Organization for Economic Co-operation and Development, SMEDAP - Small and Medium Enterprise Development Authority of Pakistan, TVET-Technical and Vocational Education and Training
\end{abstract}

\section{General Overview of MSEs}

\subsection{Background and Context}

In the first-generation era in economic development, the role of micro, small, and medium enterprises (MSMEs,) in economic development had frequently been undermined and even misinterpreted. It was believed MSMEs to slow down economic growth by attracting scarce resources from their larger counterparts (Audretsch, et al., 2000). 
Until the 1960s, it has been considered that large corporations capitalizing on economies of scale as the driving force of growth and development. The emergence of computer-based technology in production, administration and information has, however, reduced the role of economies of scale in many sectors. Many studies (e.g., Acs \& Audretch, 1993) have shown a shift in industry structure away from a greater concentration and centralization towards less concentration and decentralization which resulted into a shift towards an increased role for small firms.

This was mainly because of changes in production technology, in consumer demand, labour supply, flexibility and efficiency. These factors led to the restructuring and downsizing of large enterprises and the entry of new firms. The available evidence show that economic activity moved away from large firms to small, predominantly young firms.

Then changing patterns of consumer expenditure and demand patterns resulted in an alternative view that small business is the key element and driving force in generating income, creating employment, contributing to the local and national over all economies and realizing economic development. This paradigm shift in thinking, perspective and perception has brought a revival in the promotion of small businesses and entrepreneurial initiative at local, national and international levels.

Now, it is well accepted that MSMEs play a fundamental role in contributing to the overall economic performance of countries (Dean et al.1996; Karlsson et al. 1993). Small businesses play an important role in community development by tempting private investment back into lagging areas and spread the benefits of economic growth to people and places too often left behind. Through their capital investments, private small businesses and micro-enterprises create jobs and new opportunities that promote community-building and social activities in the rural and small towns. Hence, the economic contribution of small business to economic growth and job creation is now well recognized and established in the literature.

Proponents of policies and programs to support small firms have long claimed that they are more labor-intensive, efficient, fair in distributing the income they generate, widely dispersed geographically, and nurturing of entrepreneurs (Nichter \& Goldmark, 2005). The sector speeds up the competitive strength of a national economy by creating job opportunities for the mass, adding flexibility and industrial diversification, and making use of resources they may otherwise be drawn into the development process (Seleshi, 2001). For instance, in 2004, micro and small-scale enterprises contributed $6.2 \%$ of employment in the US, $22.3 \%$ in China, $80 \%$ in India, $67 \%$ in Japan, and 70\% in the European Union (Tegegne \& Meheret, 2011).

The micro, small and medium enterprises (MSMEs) a sector generate substantial employment and output in many countries (Nichter \& Goldmark, 2009). These authors reviewed that the sectors' share of overall employment is higher in developing countries, which are typically more focused on small-scale production. In addition, studies in five African countries (Botswana, Kenya, Malawi, Swaziland, and Zimbabwe) found that MSEs generate nearly twice more level of employment than registered, large-scale enterprises and the public sector do (Mead \& Liedholm, 1998). An ILO study (2003) examining firms with fewer than 10 workers found that they generated 58\% of total employment in Paraguay, 54\% in Mexico, and 53\% in Bolivia.

The contribution of the MSE sector to total output differs across countries. For example, MSMEs contribute approximately $31 \%$ of overall GDP in the Dominican Republic, $13 \%$ in Kenya, and $11 \%$ in Pakistan (SMEDAP, 2002).

\subsection{Horizontal Linkage}

Firms can form a cluster by themselves or organized by MSMEs officials to work together. Among the huge legal organizational options for forming horizontal cooperation are cooperatives, associations, consortia, producers' group, consumers group and other collaborative structures. This linkage helps small firms overcome many of the disadvantages of being small, providing a way to merge production, improve their bargaining power, enhance access to credit, market information and infrastructure (Goldmark \& Barker, 2005; Steen, Magnani, \& Goldmark, 2005).

Clusters (by geographical and sectoral agglomeration of enterprises) also facilitate MSMEs' growth and sustainability via enhancing horizontal and vertical linkage. Clusters inevitably involve spillover effects and pursuant of joint actions such as sharing types of machinery and materials.

\subsection{Vertical Linkage}

Firms form a vertical linkage with their buyers and suppliers. This linkage facilitates MSMEs' growth and sustainability by expanding a firm's horizon of viable business opportunities and enhancing firm capabilities. Harmony with buyers can reduce the unforeseen risks and costs connected with entering new markets by 
offering a secured flow of orders, critical information about market requirements and games, and sometimes a reduced need for capital investment (Aw, 2002). Relationship with large firms can help link rural industries to urban and international markets. This can lead to improve firm capabilities by providing opportunities for learning and innovation. To explain this, when an industrial buyer shore up with quality control, maintenance, and technical issues (Berry, Roderigus, \& Sandee, 2002) the concept of vertical linkage prevails. (e.g., MSMEs involved in Sesame production and role of College of Agriculture, Aksum University).

\subsection{Institutional Linkage}

It directly relates support provision by public institutions, technology transfer centers, legal aid centers, business leadership coaching, to MSMEs' improvements in capacity building. Besides, access to market information or innovation may help small firms respond to new opportunities. While the absence of all said above have negative impacts and are comprehended as constraints on MSMEs' growth and sustainability (Field, Hitchins, \& Bear, 2000; Gbson, Hitchins \& Bear, 2001; Lusby \& Panlibuton, 2002). There are divergent views on whether the development of markets stimulates MSE growth and sustainability (Steen et al., 2005).

\subsection{Determinants of MSMEs' Growth and Sustainability}

Following the argument by Reinikka and Svensson (2001), factors that constrain firms' investment consequently limit their growth. When MSMEs have inadequate access to relatively differentiated markets, they force them to operate in low-income market segments. This confines their levels of sales and profits since most of them compete for the same customers (Sengendo et al., 2001). Low sales and profit may depress firms' future investments and therefore their growth (Ishengoma, 2005). Thus, low profit implies internal weakness and limited resources, which may limit firms' capacities to upgrade their investments.

Identification of a firm's growth determinant factors and the relationship between/among them is complex. Cognizant to this several types of research/experts in this field have developed various frameworks. Churchill and Lewis (1983), growth model breaks the growth continuum into stages of development. At each stage in a firm's life, we commonly conceive various factors like owners' aim, managerial skill, access to capital/credit, technology application, and another start as growth determinants.

Several topologists (e.g., Mitra, 2002; Mitra \& Pingali, 2000) shed light on the issues specific to family characteristics and women-owned firms. Experts on this field identify dominant constraint factors that small business enterprises face in different growth stages. Some points in cases are starting up and working capital, leadership and market issues, prosperity and succession crisis (Patel, 1995).

Considering age, research findings on developed country MSEs have explored the association between a firm's age and growth. The studies reveal that older firms' experiences less growth (e.g., Evans, 1987; Heshmati, 2001; Variyam \&Kraybill, 1992) are consistent with developing countries works of literature. More report mixed results. For instance, Heshmati (2001) shows that while younger firms experience faster employment growth in Sweden; older firms experience faster growth in assets and sales volume. Within this context, researchers usually pay due attention to the effect of firm size and age. In the late 1980s, a debate emerged surrounding Gibrat's Law, which posits that a firm's growth is independent of size.

Contrary to the above theory, immense empirical studies find that smaller firms grow more quickly. Example, Meghana, Asli and Vojislav (2001) find that small firms with less than 2 years have the highest employment growth rates. In fact, higher sales volume and productivity growth not accompanied this. In this research, a firm's productivity and assets/sales growth were uncertain.

Besides, lack of access to credit, ranging from lack of collateral to bias against small firms, MSMEs face greater financial constraints than do large firms. A study of 10,000 firms across 80 Developing countries found that credit is mentioned more frequently by smaller firms as a severe constraint on growth (Schiffer and Weder, 2001). MSEs in these countries rarely receive credit facilities from formal banks. Thus, they rely on other types of credit such as trade credit, overdrafts, and informal sources (Bigsten et al., 2003). Microfinance institutions also provide an important source of financing for MSMEs; their outreach and terms of the loan are very limited (Swinnen, 2005).

Owing to limited access to capital, entrepreneurs across the globe typically start firms primarily through their own savings (Mason, 1998; Gebrehiwot and Amaha, 2006). To cite examples, a study over 14, 000 MSMEs in Latin America found that owners mostly used their own resources and savings (61\%) or those of their family and friends (14\%) to launch their firms (Hernandez-Trillo, Pagain, and Paxton, 2005). These findings are like the findings of the present study. The most important sources of finance for participant MSEs are personal saving, micro-finance, and families and friends. 
Developed country researchers have explored similar trends, including ranges of creative mechanisms used by smaller firms to leverage tangible and intangible assets, termed as "bootstrapping" (Lahm \& Little, 2005; Neeley, 2003). Even after MSEs overcome the start-up hurdles, lack of access to credit frequently hinders their growth during their early years, as younger firms find financing even more difficult than older firms do (Schiffer \& Wedder, 2001).

\subsection{Macroeconomic Factors}

Macroeconomic factors such as a business cycle, GDP growth, price and exchange rate stability, the regulatory and institutional environment and government policies play major roles in shaping MSMEs in developing countries. Growth opportunities are wax and wane to the swift growth of MSMEs (Liedholm, 2002). However, there are caveats, regarding the relationship between MSMEs and economic growth. Since the MSMEs in developing countries expand during an economic downturn because of an increase in a survivalist type interventions.

An econometric study in Nicaragua reveals individuals become self-used and start-up small business during bad economic times and then leaves them for salaried jobs when the economy recovers (Pisani \& Pagan, 2004)

Macroeconomic and price stability is an important factor for MSMEs' growth and sustainability (Tybout, 2000). A survey of 500 MSMEs in Ghana found that entrepreneurs perceived their three top problems to be inflation, high-interest rate, and depreciation of the local currency (Robson \& Obeng, 2008).

The regulatory and institutional environment and bad leadership are notoriously burdensome when compared with developed countries (World Bank, 2006) frequently hammers MSMEs' growth and sustainability. An econometric analysis of firm-level data in 54 countries suggests that financial, legal, and corruption challenges the growth and sustainability of this sector (Beck, Demiruguc-Kunt, \& Maksmovic, 2005)

\subsection{MSMEs Country Experience}

\section{MSE Economic contribution: India}

The contribution of micro and small enterprises (MSME) sector to manufacturing output, employment and exports of India is significant. The sector accounts for about 45 percent of the manufacturing output and 40 percent of the total exports of the country. The MSME sector uses about 42 million persons throughout the country. There are over 6000 products, ranging from traditional to high-tech items, which are being manufactured by the Indian MSMEs. A wealth of works of literature shows that the contribution of MSME sector to overall Indian industrial production is over $38.57 \%$. Besides, the contribution of the MSE sector to the gross domestic product (GDP) is over $5.94 \%$.

\section{Contribution of MSME in Malaysia}

The Census results confirmed that MSMEs are major employers in the labour market. The 518,996 MSMEs that responded to the census used over 3 million workers, accounting for $65.1 \%$ of the total employment of 4.6 million of these business establishments.

\section{MSMEs in Japan}

As a study conducted by Pushpakumara and Toshimitsu (2007) revealed that, MSMEs play a major role in every area of the national economy in Japan. Their importance is indicated by the very large share of the economy they occupy, whether in terms of several enterprises, the total number of employees, or export earnings. In Japan, in 2006, SMEs numbered 4.2 million and accounted for $99.7 \%$ of all firms compared to $0.3 \%$ of large firms. MSMEs used 42 million people, which is $78 \%$ of total employment. MSEs accounted for $47.7 \%$ of the total manufacturing shipment volume. Further, manufacturing MSMEs play a vital role in socio-economic development in Japan

\section{MSMEs in Nigeria}

We have considered small and medium enterprises as the engine of economic growth and for promoting fair development. The major advantage of the sector is its employment potential at low capital cost. The labour intensity of the MSME sector is much higher than that of the large enterprises. The role of small and medium enterprises in the economic and social development of the country is well established. The sector is a nursery of entrepreneurship, often driven by individual creativity and innovation (Adeyemi, Sidikat Laraba, 2011). It was also noted that the MSE sector is the main driving force behind job creation, poverty reduction, wealth creation, income distribution and reduction in income disparities.

Most of the government interventions did not create a much-needed transformation because of poor coordination 
and monitoring and policy inconsistencies. MSE sector also formed the vanguard of the modern enterprise sector and presents the propelling force of economic modernization and growth in Nigeria. They are an important sector that needs to be adequately factored into policymaking and programme implementation in Nigeria.

\section{MSEs Contribution to the EU Economy}

Despite their small individual size, the most striking phenomenon of MSEs is perhaps their contribution to employment in the EU economy. We found no less than two-thirds of employment in the non-financial business economy in the MSMEs sector. Of the 90 million people used in MSEs, the micro firms use 40 million, or 30\% of the total employment in the non-financial business economy. Thus, $92 \%$ of all enterprises provide $30 \%$ of total private employment and are at the same time tiny individually.

MSEs' contribution to employment growth (83\%) has been even bigger than could be expected from their share in total employment of the EU non-financial business economy (67\%). The annual employment growth rate of MSEs was more than double that of large enterprises (1.9\% versus $0.8 \%)$. In absolute terms, the number of jobs in the EU non-financial business economy increased by 11.3 million in recent periods. MSEs accounted for employment growth of 9.4 million jobs, while employment in LSEs increased by 1.9 million. In terms of value-added by sector, MSEs' contribution was highest in the services sector, accounting for $54.7 \%$ of total value added, followed by agriculture (39.7\% of total value-added of the sector) and manufacturing $(37.1 \%)$. This reflected the dominance of large enterprises in the manufacturing sector, where 1,353 large enterprises contributed about $62.9 \%$ of the total value-added of the sector. Similarly, 271 large enterprises contributed about $60.3 \%$ of total value-added in the agriculture sector.

\section{MSEs Economic Contribution Variations}

While we use less than $5.5 \%$ of the formal workforce used in SMEs in Azerbaijan, Belarus and Ukraine, this share is over $80 \%$ in Chile, Greece, and Thailand (MSME 250). Similarly, the ratio of the informal economy relative to GDP varies from $9 \%$ in Switzerland to $71 \%$ in Thailand. While the importance of informal enterprises decreases with economic development, the importance of formal micro, small and medium-sized enterprises increases. There is a steady decline in the contribution of the informal sector to GDP, from the low-income countries $(32.07 \%)$ to the high-income countries $(11.5 \%)$. Similarly, the informal sector's contribution to total employment also shows a general decline from the low-income group (41.67\%) to the high-income group $(17.9 \%)$, though it increases in the middle-income group

\subsection{MSEs in Ethiopia}

Recent pieces of literature reveal that the MSE sector in Ethiopia is the second largest employment-generating sector following agriculture (Desta, 2002). MSMEs play a fundamental role especially for women, as a strategy of poverty reduction and increasingly for employment creation (Rahel \& Issac, 2010). In successful developing countries, MSMEs because of their size, location, capital investment and their capacity to generate greater employment, have shown their powerful gelignite effect for rapid economic growth (Zewde and Associates, 2002).

The MSE sector has also helped to bring about economic transition by providing goods and services are of adequate quality and are reasonably priced, too many people particularly in rural areas, and by using the skills and talents of many people without requiring high-level training, large sums of capital or sophisticated technology (Ibid). Issuing the first national MSMEs Development and Promotion Strategy in 1997; formulation of Women Policy in 1998; the establishment of the Federal MSEs Development Agency and issuing Ethiopia's Industrial Development Strategy in 2003 aim to promote MSMEs development and empower women in particular by facilitating conditions to have access to resources and to take part in economic activities (Rahel \& Issac, 2010).

We also see the small business sector as an important force to provide the ideal environment for enabling entrepreneurs and optimally exercise their talents, to attain their personal and professional goals; generate employment and more fair income distribution; activate competition; exploit niche markets; enhance productivity and technical change through the combination of these measures, to stimulate economic development (Zewde and Associates, 2002; Desta, 2002). Rahel and Issac (2010) have shown that the role of MSMEs in employment and income generation is widely recognized, especially for women, and has become a major playing field for policymakers and donors with dual objectives of enhancing growth and easing poverty.

In the past fifteen years, Ethiopia has registered strong economic growth. The Gross Domestic Product (annual average growth in percent) of GDP, Agriculture and allied activities, industry and services from 2006 to 2010 was $11,8,10$ and 14.6 respectively (MoFED, 2010).

Considering the sectoral distribution of GDP (in percentage), 47.4, 13.6 and 39 in 2005 and 41, 13 and 46 in 
2010 in agriculture and related activities, industry and services respectively.

Similarly, Ethiopia has registered tremendous achievements in the social service sectors, particularly in the education and health sectors. Believing that MSEMs play a key role in realizing these broad-based socio-economic developments, the Government of Ethiopia has given due attention to the promotion and development of MSMEs by articulating and implementing appropriate strategic policies.

To maintain the growth momentum and achieve the envisaged Growth and Transformation Plan (GTP,) 2011-2015 goals, fostering and strengthening the small-scale and micro-enterprises is a critical strategy. Thus, MSMEs have been the pillar implementation stages of agricultural development-led industrialization (ADLI,) and shall continue to play a significant role as implementation tools of GTP (MSMEs Growth Stages Implementation Guideline, 2011)

\subsubsection{MSME Policy Overview in Ethiopia}

With the help of good governance, Ethiopia has achieved considerably fast socio-economic growth for the last consecutive years. In these last few years, we have given great attention to MSMEs with the belief they can play a crucial role in the socio-economic development of the country. The Ethiopian government has designed and implemented policies and strategies for MSMEs.

These new (January 2003 E.C) MSMEs' policy guidelines are prepared with the view and aim to sustain past best experience, to achieve the 5-year GTPI, focusing on government directions, incorporating best experiences from last five-year package and contextualized the best experience from foreign countries.

The policy document has three parts. We comprise part one of MSMEs' development strategies, MSMEs' definition, and government focus directions and enterprise, and developmental stage-based support of MSMEs'. Part two contains the objectives of MSMEs' development support strategies, human capital and technological growth, a provision of market opportunity and place, finance and loan service, shade centers development and comprehensive service centers development strategies. The third part contains policy initiatives like support institutes' capacity building and the role of policy implementing bodies.

\subsubsection{MSMEs Development and Ethiopian Renaissance}

MSMEs have a very crucial place in the Ethiopian industrialization plan. This is because the focal point of Ethiopia's economic development plan is to create job opportunity and MSMEs are the most important means of job creation, especially in towns. This is true not only in developing countries but also in developed countries like Japan. Ethiopia gives attention to MSMEs especially the manufacturing sector as they are the key to production and industrialization. For instance, Japan, which is highly industrialized, gets over $50 \%$ of its manufacturing products from MSMEs.

MSEs are the main actors of industrial growth not only during the Ethiopian renaissance journey but also after we complete this journey. We transfer a considerable number of MSEs to medium and large enterprises. Thus, MSEs are main sources of industrialization and developmental capital owners. Therefore, it is the right decision for Ethiopia to focus on MSMEs' development.

Besides the above reasons, the Ethiopian Government has political reasons to focus on MSMEs. The government (EPRDF) has succeeded to have a strong base in the farmer which about $85 \%$ of the population. EPRDF gets strong support from the wealthy farmer and it has achieved keeping and enhancing the farmers' benefit. The Ethiopian government wants to attract the town dwellers. Those with less capital but more labour are especially targets of interest as they can fit to take part in MSMEs. Therefore, in this way the government can mobilize the entire population to the motion of socio-economic development through agriculture and MSMEs.

Among the attention and support given to MSMEs by the Ethiopian government are to fight rent seeking thinking, solving technological, skill, and capital and market problems. Thus, with a belief that MSEs can play an important role in the Ethiopian renaissance, the Ethiopian government is highly committed to making and implementing favourable policies and strategies for MSMEs.

\subsubsection{MSMEs' Development Strategies}

The main objectives of the strategies are:

$>$ Increase the income of citizens, reduce poverty, and create a fair distribution of capital by creating vast job opportunity.

$>$ To sustain agricultural development and make it a basis for industrialization.

$>$ Create competent and sustainable fast growth. 
> To diversify MSMEs' development by creating big developmental capital owners in towns.

To achieve these objectives, the strategies focus on important MSMEs' development directions. These directions include general development, human capacity building, technological growth, financial source and provision, production and market place provision, market linkage and opportunity, comprehensive and central service, industrial extension service, capacitating supportive bodies and comfortable working environment. There are important strategies of support to develop MSMEs. Best experiences and constraints in MSEs are also well assessed to help easily implement the support strategies and develop MSMEs.

The Ethiopian government has given special focus to export and manufacturing products which can substitute imported goods. We give the MSME policy shows two sectors which can create vast job opportunities to enjoy manufacturing, construction, petty trade, service and agriculture.

\subsubsection{MSEs' Development Based Support and Initiatives}

We base the support given to MSMEs on their developmental stage or growth. We can classify support as start-up, growth, and maturity supports.

They enjoy supports given at start-up stage providing start-up capital, motivate and facilitate the enterprises to legally register, BDS and entrepreneurial capacity building and technical pieces of training. They support MSMEs at a growth stage in finance, skill and technology capacity, linkage and market opportunity, diversification and provision of production and market centres, and making them legal. Finally, MSMEs at maturity stage are given supports enjoy enhancing their competency; providing tools and material ease that can help them transfer from small to the medium enterprise; recognize and certifying those transferred to medium enterprises.

We list here the initiatives which help achieve the strategic objectives and.

$>$ Capacity building of supporting institutes

- TVETs

- MSME development agencies (Federal \& Regional)

$>$ Capacity building of micro-finance institutes

$>$ Capacity building of every hierarchical management and actors of MSMEs

$>$ Identifying and informing the roles of different bodies who are to implement the strategy.

$>$ Putting and communicating the objectives and tasks of MSEs to stakeholders.

\subsubsection{Definition of MSMEs in Ethiopia}

According to the revised Micro and Small-Scale Enterprises Growth Stages Guideline No.004/2011, the revised definition considers used labour force including family labour; total assets without working building and the division of sub-sector into service and industry are the main criteria.

\subsubsection{The Revised Definition of Micro Enterprises}

A. Industrial sector (includes manufacturing, construction and mining sub-sectors)

A business enterprise which uses not over five labour force including business owner and family labour and/or the monetary value of the enterprise's total asset is not over $100000 \mathrm{Br}$.

B. Service sector (includes retail trade, transport, hotel and tourism information technology and repairs)

A business enterprise which uses not over five labour force including business owner and family labour and/or the monetary value of the enterprise's total asset is not over $50000 \mathrm{Br}$.

\subsubsection{The Revised Definition of Small Enterprises}

A. Industrial sector: (includes manufacturing, construction and mining sub-sectors)

A business enterprise which uses 6-30 five labour force including business owner and family labour and/or the monetary value of the enterprise's total asset ranging100001-1500000 Br.

B. Service sector: (includes retail trade, transport, hotel and tourism information technology and repairs)

A business enterprise which uses 6-30 five labour force including business owner and family labour and/or the monetary value of the enterprise's total asset ranging50001-500000 Br. According to the revised guidelines mention above, when the labour force used, and monetary value of an enterprise's total asset do not conform; the latter prevails. 
Table 1. Classification of MSEs

\begin{tabular}{llll}
\hline $\begin{array}{l}\text { Enterprise } \\
\text { Size }\end{array}$ & Sector & $\begin{array}{l}\text { An asset in Birr } \\
\text { working building) }\end{array}$ & $\begin{array}{l}\text { (excluding } \\
\text { Micro }\end{array}$ \\
& $\begin{array}{l}\text { Service } \\
\text { Industry }\end{array}$ & $\begin{array}{l}\text { Not over } 50000 \\
\text { Not over } 100000\end{array}$ & Not over 5 individuals \\
\multirow{2}{*}{ Small } & Service & $50001-500000$ & \\
& Industry & $100001-1.5$ million & $6-30$ individuals \\
\hline
\end{tabular}

Source: MSEs' Development, Support Scheme, and Implementation Strategies: FDRE, January 2011, Addis Ababa

\subsection{MSMEs in Tigray}

In Ethiopia there are inadequate opportunities in the formal sector employment to soak up rural people and new urban entrants into the labour market and creating a formal sector employment is a major challenge. We constrain many people into marginal activities in the informal sector as subsistence petty traders and tiny handicraft producers with a limited market scope that are often categorized as micro, small and, medium enterprises (MSMEs). It thus gives MSMEs special attention by the government as they comprise the largest share of total enterprises and employment in the non-agricultural sector.

This sector creates huge employment as they are small business activities, family-based and often reliant on workers with skills and experiences specific to the enterprise.

Unemployment is one of the critical social problems of Ethiopian towns and that of Tigray in particular. The urban unemployment rate in Tigray was about $13.7 \%$ and $21.1 \%$ in 2006 and 2009 respectively (CSA, 2009).

Tigray Regional Trade and Industry Bureau (the client of this study) is promoting and supporting micro, small, and, medium enterprises. It designs strategic policies and creates an enabling the environment to the target group by acclimatizing comprehensive approaches such as business development service approach, information centres, incubation centres and cluster approach.

However, those antipoverty interventions introduced and being implemented by the government ought to be continuously scrutinized in terms of its contribution to employment creation, poverty alleviation, total final output production and women empowerment, the possible sectoral, industrial, market, institutional and industrial linkage and growth and sustainability determinants.

Finally, an unexploited potential area of the region in micro, small, and medium enterprises should be discussed as it ensures the prospects and sustainability of the sector by diversifying and integrating it instead of concentrating on limited sectors and producing identical products.

\subsection{Statement of the Problem}

Although flourishing MSMEs contribute significantly to the national economy by easing poverty through income generation, contributing to the socio-economic by empowering women, employment creation, contribution to the gross domestic product (GDP), being vanguards of industrialization and core pillars for economic and structural transformation by promoting saving and capital accumulation. Until recently, governments of developing countries, the development communities and development agents have never given the MSME sector apposite recognition and support from the Ethiopian government (Eshetu \& Zeleke, 2008). Besides, the MSME sector in Ethiopia faces several constraints that hold back its rapid growth and development and therefore reduce the weight of its potential contribution to the national economy and inhibit the economic empowerment of women (Zewde \& Associates, 2002).

In recent years, the Ethiopian government has articulated strategic policies to promote and support micro, small and medium enterprises. As it has been an instrumental implementation stage of the Plan for Accelerated and Sustainable Development to End Poverty (PASDEP) (2005/06-2009/10). Besides, it is succinctly outlined in the Growth and Transformation Plan (GTP) (2011-2015/16) that this sector shall continue to play a critical role in achieving the GTP's envisaged objectives.

Why does the Ethiopian Government prioritize this sector? The rationale for prioritizing this sector is that in any endeavours of poverty alleviation MSEMs play a critical role as the poor with limited skill and start-up capital can take part in wide ranges of petty business activities. 
Not only this sector creates employment and generates income for the poor but also helps them enjoy economic growth by consuming domestic investment. By joining the limited capital and skill of the poor, now they can take part in large projects impossible before. Even the individual MSMEs who did not have access to startup capital and workplace have now the opportunity to engage in income generating economic activities.

In this context, unemployment is a big concern in Ethiopia as well as in Tigray. The civil service structure in the region is over-saturated. As there are over 70,000 civil servants (many of them being teachers, police forces and development agents). Hence, there is no vacant space to generate employment opportunities to the gigantic youth prospect graduate from TVETs and Universities (unpublished regional parliamentary report, 2009/10).

Uniquely, though the private sector (like EFFORT) in Tigray plays a significant role in generating employment opportunities; unemployment is rising especially in urban areas $13.7 \%$ and $21.1 \%$ in 2006 and 2009 respectively (CSA, 2009).

Creating employment is a hard pressing issue in the region. We mean the development of MSMEs to open great job opportunities in the region. However, the constraints to and opportunities for the growth of such enterprises have not been systematically studied. This, therefore, has resulted in a paucity of information in the sector. As the sector has a dynamic behaviour, we require continuous research as input for developing informed policies and strategies to create an enabling environment to further support and nurture the enterprises. Human capital skill gap, innovation, product and market development, government and public policy coordination failure and sources of finance are among critical challenges that may numbered the development dimensions of considering MSMEs as vanguards of industrialization in transforming the economy and society of developing countries Weldeslassie, $(2017$.

We expect refinements in the methodological, empirical and policy research methods and approach. The dynamic nature of the sector implies that there is a need to undertake a survey to explore the status and prospects of MSMEs in the region to solicit and articulate policy options. Thus, this study aims at investigating the current status of MSMEs and providing analytical information that guides the regional government in the formulation of public policies; institutions and infrastructural development affecting this sector; capitalizes its importance in bringing about sustainable development in the region. The study also aims at assisting government and non-government organizations to design intervention strategies to help these enterprises and play their role in achieving the GTP.

Finally, this study examines MSMEs in Tigray and explores how they contribute to sustainable poverty alleviation, GDP, women empowerment, employment opportunities; market-industry- linkage, dynamics, challenges and prospects.

\subsection{Objectives of the Study}

The general aim of this study is to investigate the current status of MSMEs in Northern Ethiopia with particular emphasis in Tigray. Specifically, it is aimed to:

$>$ assess the contribution of MSMEs to the macro-economy in terms of employment generation, women empowerment, GDP growth (gross value added);

$>$ investigate the MSMEs growth and sustainability determinants;

$>$ examine MSMEs market-linkage; and

$>$ Scrutinize the contribution of MSMEs to industrial growth.

\subsection{Data Sources and Methods}

\subsubsection{Methods of Data Collection}

Data for the study have been collected by administering a structured interview that contains both open- and close-ended questions, documents review, focus group discussions and interviews with focal persons. To do this, 20 enumerators have been recruited and trained for two days on data collection methods and on contents of an interview guide. Subsequently, enumerators in collaboration with supervisors have filled interview guides. We have collected secondary data from sectoral reports, manuals, policy documents, focus group discussion and previous research works.

To take the participants for the study lists of MSMEs clustered by sectors we collected lists of MSMEs clustered by sectors from local administration trade and industry offices of each sample town. Then, MSMEs were selected randomly using proportional stratified random sampling technique from each town in each MSME type and sector. About an interview with a focal person, we collected data from Trade, Industry and Urban 
Development Administrators and MSME Officials of each town.

Specifically, a cross-sectional stratified random survey was conducted to get data on basic household information (age, gender, and education level), household and group members' income, business establishment information, enterprise characteristics, group formation, MSMEs performance, sources of finance, BDS and Need-Based Training, markets and market linkages, women empowerment, MSMEs constraints and issues of raw material, industrial linkage and growth and survival determinate.

\subsubsection{Pilot Survey}

After a pre-test and continuous discussion with the client, we conducted a pilot survey in Mekelle from Jan. $15-23,2011$ by taking a random sample comprising 50 participants from all sub city administrations of the state city. Then, we thoroughly revisited and changed the interview guidelines based on the feedback from trainees. We conducted the whole survey from Feb 8- March 5, 2011. Data management, analysis and preliminary report writing March10-May 30, 2011. This research is then enriched, developed and improved based on the various discussions with governments, key informants and the MSMSs based on the preliminary report.

To check the effectiveness of research method and be alert about some unanticipated difficulties in the survey data for the study have been collected by administering a structured interview that contains both open- and close-ended questions, documents reviews, focus group discussions and interviews with focal persons. To do this, 20 enumerators have been recruited and trained for two days on data collection methods and on contents of an interview guide. Subsequently, enumerators in collaboration with supervisors have filled interview guides. We have collected secondary data from sectoral reports, manuals, policy documents, and previous research works.

To take the participants for the study, we collected lists of MSMEs clustered by sectors from local administration trade and industry offices of each sample town. Then, MSMEs were selected randomly using a stratified random sampling technique from each town in each MSME type and sector. About an interview with a focal person, we collected data from Trade, Industry and Urban Development Administrators and MSEMs Officials of each town.

\subsubsection{Study Area Description}

The study area, Tigray, is in northern Ethiopia and has a rugged terrain, ranging between 400 to almost $4000 \mathrm{~km}$ above sea level, covering a total area of $53,000 \mathrm{~km}$. It lies between latitudes $12^{\circ} 15^{\prime} \mathrm{N}$ and $14^{\circ} 57^{\prime} \mathrm{N}$ and longitudes $36^{\circ} 27^{\prime} \mathrm{E}$ and $39^{\circ} 59^{\prime} \mathrm{E}$.

We structure the region into seven administrative zones and 36 districts (Fig. 1), and we estimate its population to be about 6.5 million of which $80 \%$ live in rural areas. The climate is predominantly semiarid with irregular rainfall and frequent drought periods. Average annual rainfall ranges between 500 and $900 \mathrm{~mm}$, with a unimodal pattern, except in the southern part of the study area where a second, smaller rainy season allows local growing of two successive crops within one year (Nyssen et al. 2005).

The seven zonal administrations of Tigray regional state are Western, North-Western, Central, Eastern, South-Eastern, Southern and Mekelle special zones. According to CSA 2007 census (2008), it has a population of $4,314,456$, where over $19.53 \%$ of the population lives in urban areas. In terms of sex distribution, close to $50 \%$ of the population are females. Amongst the Urban residents, the female population amounts to $52.76 \%$. This number is slightly greater than females that live in rural Tigray that comprise $50.26 \%$. Considering the age cohort, $51.87 \%$ of Tigray population falls between 15 and 64 ; whereas over $60 \%$ of the urban population is in the working age group.

The study is conducted on eighteen towns of the region, namely Alamata, Korem, Maychew, Mekelle (North and South Woreda), Wukro, Adigrat, Abi-Adi, Adwa, Aksum, Shire, Humera, Sheraro, Enticho, Mekoni, Adi-Gudom, Freweini, and Dansha. The client, Bureau of Trade and Industry in collaboration with the consultant, Aksum University research team selected these sites. The reason for selecting the sample towns mentioned above was because there is a high accumulation of MSMEs in these towns. The first twelve towns are town woreda administrations and the last six towns are emerging towns from each zone.

We locate all towns at a considerable distance from the heart of the state-city (Mekelle-Tigray). Alamata, Korem, Maychew, Mekoni and Adi-Gudom 187, 127, 164, 126 and $37 \mathrm{~km}$ to the South of Mekelle, respectively. Mekelle (North and South Woredas), the capital city of regional government comprises seven sub city administrations. Wukro, Freweini and Adigrat are located 46, 78 and $115 \mathrm{~km}$ to the North and North-West of Mekelle, respectively. Abi-Adi, Enticho, Adwa and Axum are located 95,177, 219 and $244 \mathrm{~km}$ to the North-West, East of Mekelle respectively. Shire, Sheraro, Humera and Dansha are located 307, 402, 590 and $695 \mathrm{~km}$ to the West of Mekelle respectively (Bureau of Construction, Road and Transport, 2011).

As far as climate is concerned, Dansha, Humera, Sheraro, Alamata and Abi-Adi have tropical "kola" 
Agro-ecological zone. Whereas, Shire, Axum, Adwa, Enticho, Adigrat, Wukro, Mekelle, Freweini, Adi-Gudom and Mekoni are in the midland (weina dega) agro-ecological zone. Finally, Maychew and Korem have a temperate (dega) Agro-ecology.

\subsubsection{Sampling}

The survey is aiming at collecting relevant data on MSMEs in northern Ethiopia, with special reference to Tigray. It tries to assess the contribution of MSMEs to the macro-economy in terms of employment generation, women empowerment, and GDP. It is worth mentioning that MSMEs' contribution to industrial growth, dynamics of MSMEs, linkage to market, challenges and opportunities they face are also integral parts of this survey.

Sample MSMEs selected for the study was derived from the 2008 Ethiopian census. We selected them from 18 towns (12 big and 6 emerging towns) of the region applying probabilistic and non-probabilistic sampling techniques. The research team and Tigray Regional State, Bureau of Planning \& Finance selected purposively the 18 towns (the client). We selected these towns because there are many MSMEs are found mainly in urban and semi urban areas. Then, a sample that contained 1500 MSMEs were selected using proportional stratified random sampling from the selected towns. We prefer this technique because it is convenient to take participants from the strata of towns and sectors. We classify the MSMEs as Construction, Metal and Woodwork, Services, Petty Trade, Urban agriculture, Textile and Handicraft. We calculated the following to select the number of participants MSMEs from the towns and sectors using the following formula:

$$
n_{i}=N_{i}^{*} n / N
$$

where $\mathrm{N}=$ population size

$\mathrm{n}=$ sample size $=1500$

$\mathrm{N}_{\mathrm{i}}=$ size of $\mathrm{i}^{\text {th }}$ stratum

$n_{i}=$ number of participants selected from the $i^{\text {th }}$ stratum

Once the number of MSMEs to be selected from each town and we determine each sector, the respective researcher assigned to each town selected the participants using simple random sampling. Here, 2002 E.C. survey lists of MSMEs were obtained from kebele and MSME offices (i.e., a list of private enterprises was obtained from kebele offices and that of group enterprises from MSME offices) and the actual participants were randomly selected in their names. The enumerators' team located and interviewing the selected participant MSMEs using the interview guide. We find the number of selected enterprises by sector and location in annex-1.

\subsubsection{Methods of Data Analysis}

The models used in this research include log-linear, logistic models, FGT, a residual approach. I used STATA15 software package to analyze descriptive and inferential statistics. We present data in the form of Tables, Figures and Graphs.

\section{Characteristics of MSEs}

In this section, we shall present a brief description of data on the business sector, size category of firms, current MSMEs' asset, MSMEs' age, type of ownership, the situation of workplace, recording habit of the transaction and sources of finance.

\subsection{Size Distribution of MSEs by Sector}

Table 2 illustrates the size share of MSMEs together with mean asset and share of firms. Looking at the size of firms by the mean asset of the total, $2.4 \%$ are micro-enterprises with the capacity of employing $64 \%$ of the total employment created by MSEs in the study. The percentages of small enterprises are $14.6 \%$ and the employment generated by these firms is $35 \%$ of the enterprises examined in this research. The proportion of medium and large enterprises by mean assets are $83 \%$. However, medium and large enterprises only create $1 \%$ employment opportunity.

Considering the size of MSMEs by a share of firms (number of firms in each category), $66.8 \%, 32.2 \%$ and $1 \%$ drop on micro, small and medium and large enterprises, respectively. These findings show that even though the majority (99\%) of the enterprises is MSMEs as expected, there are enterprises which do not belong to the group. This may bring two problems. First, it may affect the enterprises' moral and demotivate them. Though the enterprises are expected to be graduated, they are still treats as MSMEs. Second, these enterprises already 
grownup, and supposed to be graduated and engage in other area are still competing with MSMEs in getting support which they do not deserve.

Considering the size of firms by mean asset and MSEMs sub-sectors, of the micro-enterprises, the manufacturing sub-sector has the highest share $(0.8 \%)$ followed by the construction sub-sector. While the rest subsectors under this category have a similar share of mean assets. When we look at the right-hand side three columns of table 2 below, it displays size by a shade of firms (frequency) in each MSEMs sub-sector. In this context, petty trade has the highest share of firms $(20 \%)$ followed by the construction $(17 \%)$ and manufacturing sub-sectors of the micro-enterprises. Similarly, petty trade $(14 \%)$ has the highest share in the small MSEMs sub-sectors yet followed by services $(9 \%)$ and urban agriculture $(5 \%)$ sub-sectors. When we consider the two size categories (mean asset and share of firms) and MSEMs sub-sectors, medium and large enterprises have the highest share in the former and smallest share in the latter.

Recently, there is a high price inflation of commodities and high demand for construction mainly because of economic growth and the expansion of institutions, universities, and housing development. Here, MSMEs can serve as the best strategies to satisfy these demands.

In sum, of the total mean asset share of medium \&, large firms are $83 \%$ while their share by size (frequency) is $1 \%$. However, these firms use $1 \%$ of the total MSEMs survey employment creation. Whereas mean asset share of micro-enterprises is $2.4 \%$ though their share by size (frequency) is $66.8 \%$ and create employment opportunities to $64 \%$ of the total employment created by survey MSMEs. Medium and large enterprises are enjoying governmental support as small firms though supposed graduate.

Table 2. MSMEs size distribution by sector, mean asset and share of firms

\begin{tabular}{lllllll}
\hline \multirow{2}{*}{ Sector } & \multicolumn{3}{c}{ Size by a mean asset (\%) } & \multicolumn{3}{c}{ Size by share of firms (\%) } \\
& Micro & Small & Medium and large & Micro & Small & Medium and large \\
\hline Manufacturing & 0.8 & 3.6 & 0 & 12.99 & 1.02 & - \\
Construction & 0.7 & 4.5 & 31 & 16.57 & 4.01 & .08 \\
Petty trade & 0.3 & 2.2 & 12 & 19.71 & 13.58 & 0.37 \\
Urban Agriculture & 0.3 & 2.3 & 20 & 7.52 & 5.11 & 0.32 \\
services & 0.3 & 2 & 19 & 10 & 8.54 & 0.23 \\
share of total firms & 2.4 & 14.6 & 83 & 66.8 & 32.2 & 1 \\
Employment & 64 & 35 & 1 & 64 & 35 & 1 \\
\hline
\end{tabular}

\subsection{Firms' Age and Sectorial Distribution}

Figure 1 shows a life span of MSMEs in each sector. They classify ages of MSMEs into four: $\leq 3,3<\mathrm{x} \leq 6,6<$ $\mathrm{x} \leq 9$, and $>9$ years of age. It draws the ages of MSMEs from their year of establishment. Figure 1 depicts that, there are younger MSMEs in the age range of three years and below. One can observe that MSMEs have boomed over the last three years especially in the construction (157 enterprises/ 23.93\%) and trade (130 enterprises/ $19.82 \%$ of those reported this information). This is because of the growing economic development we can observe and special attention of the government to MSMEs.

As already seen in Table 2 construction, manufacturing and service sectors are contributing more and diversifying in these sectors may be more helpful. There are younger MSMEs in the construction, trade, and service sectors. Studies show that young enterprises grow more rapidly and contribute better than older enterprises. The relationship between firm age and small firm growth in developing countries is robust (Nichter \& Goldmark, 2005; 2009). This may inform policymakers and administrators to always have newly established or young enterprises (MSEs) in the selected sectors. 


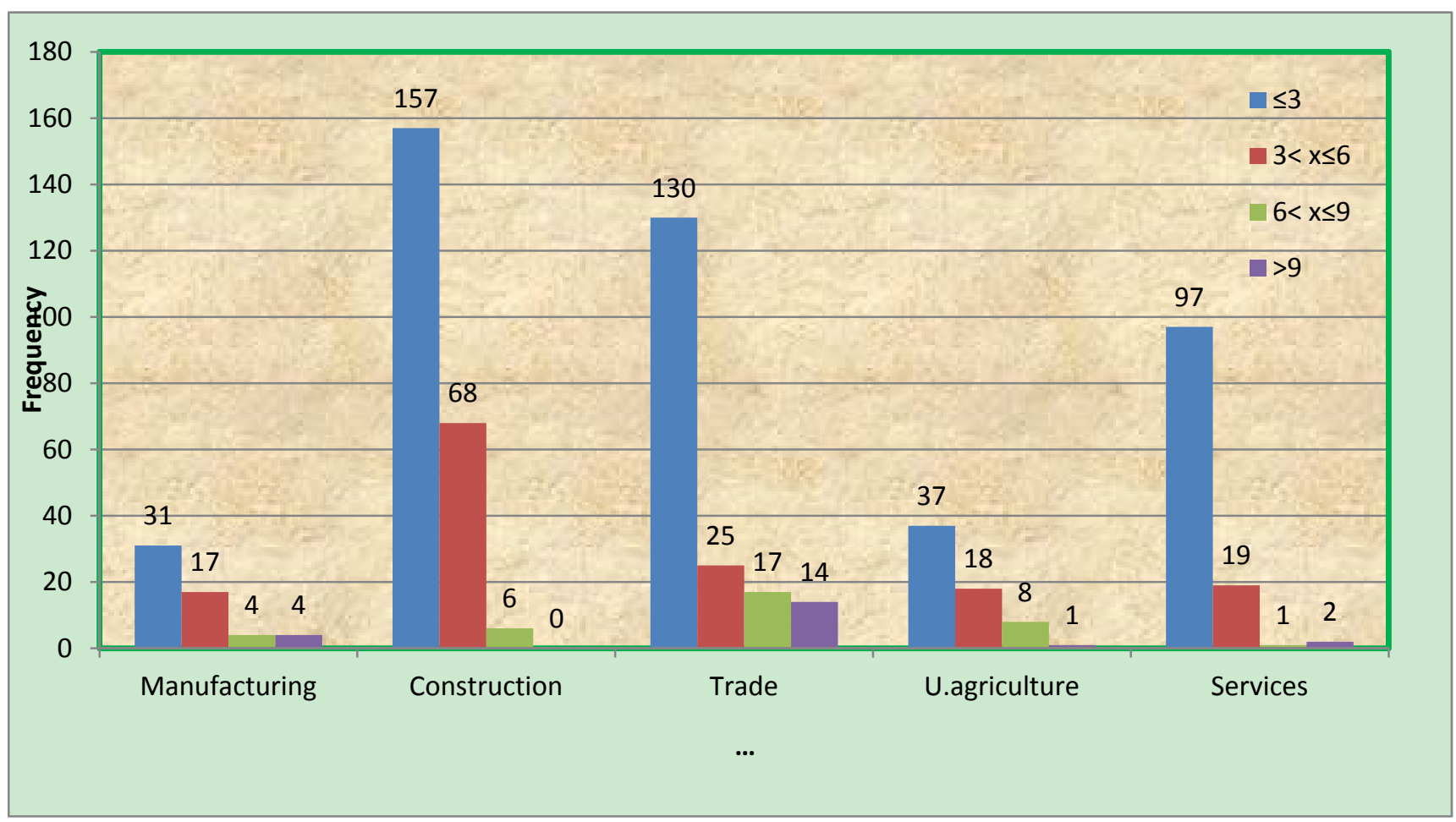

Figure 1. MSEs' age

\subsection{MSEMs Business Ownership (Legal Status)}

Table 3. shows that most MSMEs are in a sole proprietorship (744 enterprises or 52.28\%) and cooperatives (596 enterprises or $41.88 \%$ ) ownership form. While most of the participants from the construction sector are cooperatives (243 enterprises or 91.01\%), participants from the trade are run by sole proprietors (308 enterprises or $69.21 \%$ ). All construction and most of the service and manufacturing MSMEs have legally registered. Relatively high numbers of trade and urban agriculture sectors have no legal status. Even though the majority (97.75\%) of the participant MSMEs has legally registered, there are some with no legal status. And these informal MSMEs will not get any support. The informality of MSEs reduces chances for growth and is associated with several other characteristics that make growth difficult (Nichter \& Goldmark, 2005).

Table 3. MSEMs ownership (Legal Status)

\begin{tabular}{llllll}
\hline Sector & Sole proprietorship & Simple partnership & Cooperatives & No legal status & Total \\
\hline Manufacturing & 176 & 9 & 112 & 4 & 301 \\
Construction & 18 & 6 & 243 & 0 & 267 \\
Trade & 308 & 28 & 94 & 15 & 445 \\
Urban agriculture & 105 & 1 & 47 & 10 & 163 \\
Service & 137 & 7 & 100 & 3 & 247 \\
Total & $\mathbf{7 4 4}$ & $\mathbf{5 1}$ & $\mathbf{5 9 6}$ & $\mathbf{3 2}$ & $\mathbf{1 4 2 3}$ \\
\hline
\end{tabular}

\subsection{Workplace for Business Enterprises}

Table 4 presents the place where entrepreneurs run their business. The table shows that a considerable proportion (43.18\%) of the participant MSMEs run their business in separate rooms. This shows that many entrepreneurs run their business in a separate place, and this may help them focus on their business. Separate working places have probably good market opportunity. One-fourth of the participants MSMEs run their business in living rooms and nearly one-fourth in a rented house. Relatively few entrepreneurs use shades to run their business. Despite the claim's entrepreneurs pose for not getting a working place, only a few of them are using shades to run their 
business. But this is open for further investigation. Are there enough shades and/or are the shades need-based and suitable market places?

Table 4. Business enterprise's workplace

\begin{tabular}{lll}
\hline Workplace & Frequency (f) & Percent (\%) \\
\hline Living room & 369 & 25.70 \\
Separate room & 620 & 43.18 \\
In shades & 131 & 9.12 \\
In a rented house & 316 & 22.01 \\
Total & $\mathbf{1 , 4 3 6}$ & $\mathbf{1 0 0 . 0 0}$ \\
\hline
\end{tabular}

\subsection{Recording Habit of Transactions}

Table 5. Recording of transaction

\begin{tabular}{llll}
\hline Sector & Recording of Transaction & & Total \\
& Yes & No & 311 \\
\hline Manufacturing & 190 & 121 & 267 \\
Construction & 227 & 40 & 435 \\
Trade & 292 & 143 & 163 \\
Urban agriculture & 109 & 54 & 247 \\
Service & 190 & 57 & $\mathbf{1 4 2 3}$ \\
Total & $\mathbf{1 0 0 8}$ & $\mathbf{4 1 5}$ & $\mathbf{1 0 0}$ \\
Percent & $\mathbf{7 0 . 8 0}$ & $\mathbf{2 9 . 1 6}$ & \\
\hline
\end{tabular}

While nearly three-quarters of the entrepreneurs kept records of their transactions, a minority of them did not (see Table 5). We can observe that a considerable proportion of entrepreneurs $(29.16 \%)$ do not use a book of records. We found this to be serious limitation, and it is mainly because of knowledge and skill about the issue. This problem can easily be minimized by supporting entrepreneurs with BDS and related pieces of training.

\subsection{Sources of Finance to Run the Business}

MSMEs used various sources of finance to run their businesses. Table 6 shows the finance sources of entrepreneurs to run their MSEs or businesses. The most common source of finance that entrepreneurs used to run their business is personal saving. This result shows encouraging performance in saving and it needs further strengthening and scaling up. The second important source is a formal loan from micro-finance. Microfinance institutions are very helpful as they are easily accessible. Family or friends and personal asset are also the third and fourth sources. These results are consistent with that of Gebrehiwot and Wolday (2006), "we have seen that family or friends is widely practised among MSEs; that most of the trade credit-recipient (family or friends) MSEs lack access to bank loans; that MSEs that receive trade credit is also likely to give trade credit (in effect, passing on the credit) and that MSEs mainly depend on single primary suppliers." 
Table 6. Sources of finance to run the business

\begin{tabular}{llllllll}
\hline \multirow{2}{*}{ Source } & \multicolumn{2}{l}{ Frequency (mark out of 5) } & \multicolumn{3}{c}{ Total score } & \multirow{2}{*}{ Rank } \\
\cline { 2 - 7 } & $1(\%)$ & $2(\%)$ & $3(\%)$ & $4(\%)$ & $5(\%)$ & & \\
\hline Personal saving & $224(19)$ & $72(6.10)$ & $154(13.1)$ & $135(11.4)$ & $595(51)$ & 4345 & 1 \\
Family or friends & $372(48.1)$ & $45(5.8)$ & $120(15.5)$ & $111(14.3)$ & $126(16.3)$ & 1896 & 3 \\
Informal saving (like equub) & $425(63)$ & $57(8.5)$ & $98(14.6)$ & $83(12.4)$ & $7(1)$ & 1200 & 5 \\
Formal bank loan & $599(87.8)$ & $27(4)$ & $22(3.2)$ & $15(2)$ & $19(2.8)$ & 874 & 7 \\
Personal asset & $352(49.9)$ & $44(6)$ & $133(18.8)$ & $82(11.6)$ & $95(13.5)$ & 1642 & 4 \\
A formal loan from micro-finance & $346(43.2)$ & $30(3.8)$ & $49(6)$ & $99(12.4)$ & $277(34.6)$ & 2334 & 2 \\
Money Lenders & $552(81.2)$ & $45(6.6)$ & $47(7)$ & $21(3.1)$ & $15(2.2)$ & 942 & 6 \\
\hline
\end{tabular}

\section{MSMEs Contribution to Regional Economy and Performance}

In this chapter, we attempted to comprehend the role of MSMEs and their contribution to the regional economy in terms of employment creation, output, poverty reduction, and women's empowerment in Tigray. Towards the end of this chapter, we analyze the determinants of MSMEs' growth performance with the help of econometric investigation.

\subsection{MSMEs Employment Contribution}

3.1.1 Employment by Size Category

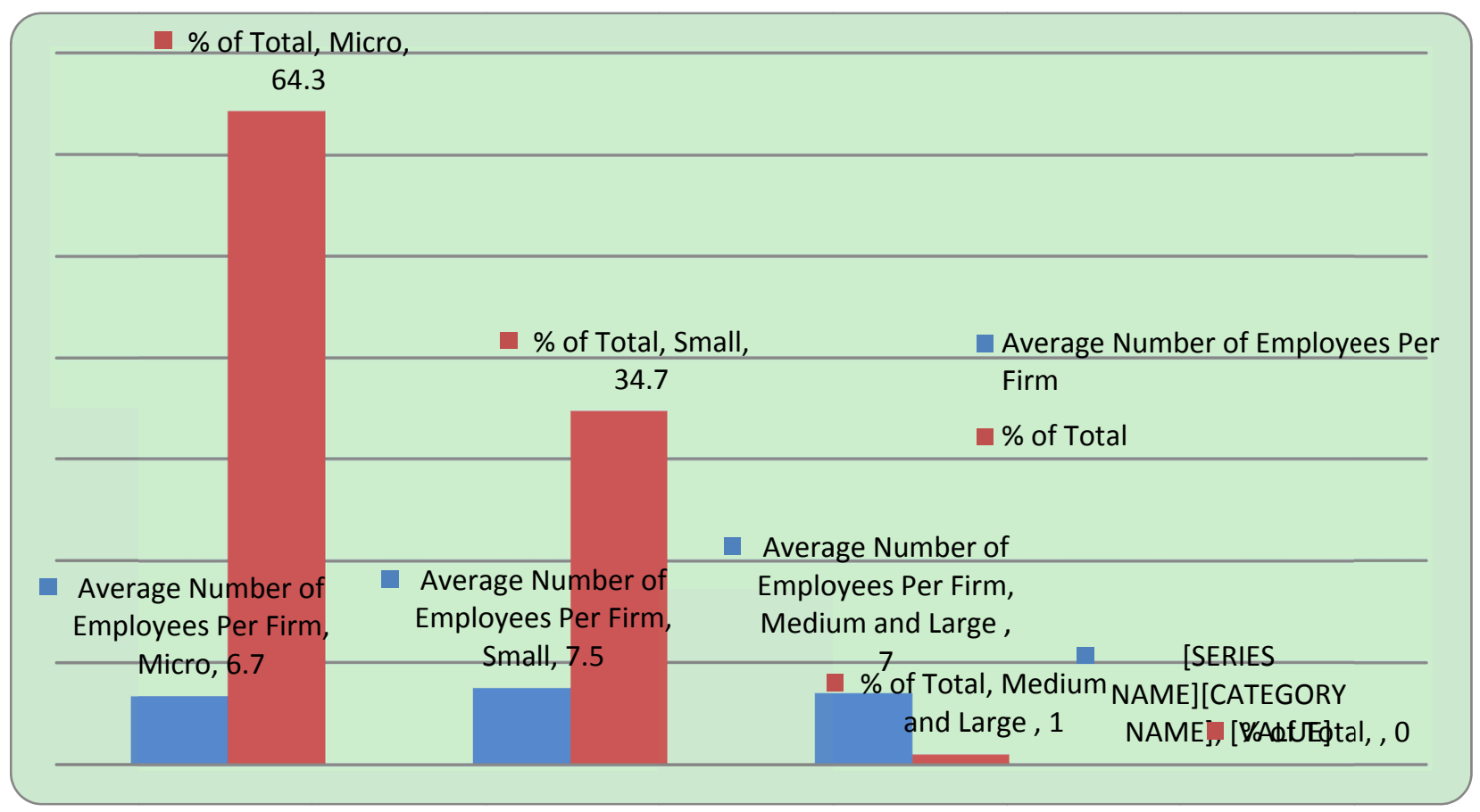

Figure 2. Average numbers of workers per firm by firm size category

Figure 2 above reveals information regarding employment according to firm size. They use nearly $99 \%$ of employees in MSMEs while Medium and Large enterprises use only 1\%. Our findings are like previous studies conducted in developing countries (see Ayyagari et al., 2011). The figure also shows that the average number of workers per firm is similar regardless of size. 


\subsubsection{MSEs Business Ownership and Employee}

Table 7. Average number of workers per firm by ownership form

\begin{tabular}{lll}
\hline Ownership Type & $\begin{array}{l}\text { Average Number of } \\
\text { Employees Per Firm }\end{array}$ & \% of Total \\
\hline Sole proprietorship & 5.6 & 43.1 \\
Partnership & 6.5 & 2.6 \\
Cooperatives & 8.5 & 53.3 \\
Total & 6.8 & 100 \\
\hline
\end{tabular}

Firms differ in size according to their legal status as seen in Table 7. Cooperatives create the highest job opportunity with an average of 8.5 employees per firm and which account $53.3 \%$ of the total employment. A sole proprietorship has an average of 5.6 employees per firm but accounts for $43.1 \%$ of total employment. Partnership firms create a job on average for 6.5 workers. While several workers per firm in partnerships is high compared to sole proprietors, their contribution to the total employment is minimal $(2.6 \%)$.

\subsubsection{Employment by Sector}

Table 8. Employment by sector

\begin{tabular}{lllll}
\hline \multirow{2}{*}{ Business Line } & \multicolumn{5}{c}{ Average Employment by Firm Size } \\
\cline { 2 - 5 } & Micro & Small & Total & \% of Total \\
\hline Manufacturing & 5.3 & 5.5 & 5.4 & $\mathbf{1 5}$ \\
Construction & 8.5 & 9 & 8.8 & $\mathbf{2 5}$ \\
Petty trade & 6.1 & 7.3 & 6.7 & $\mathbf{1 9}$ \\
Urban Agriculture & 7.5 & 7.5 & 7.5 & $\mathbf{2 1}$ \\
Service & 6 & 7.5 & 6.8 & $\mathbf{2 0}$ \\
Total & & & $\mathbf{3 5 . 2}$ & $\mathbf{1 0 0}$ \\
\hline
\end{tabular}

Employment also differs by sector, as Table 8 shows. The greatest percentage of employees is engaged in the construction sector accounting approximately $25 \%$ while urban agriculture ranks second as it uses nearly $21 \%$ of the total MSMEs employment. For micro-enterprises, employment per enterprise is highest in construction and urban agriculture ( 8.5 and 7.5 respectively). Among small firms, the average employment per enterprise is higher in the construction sector.

\subsection{MSEMs Output Contributions}

\subsubsection{Sectoral Contributions}

In this subsection, the relative contributions of MSMEs to the regional economy in terms of Gross Value Added are presented. They calculate it as the residual of the units' total output less intermediate consumption (that is, goods and services used up in producing the output) ${ }^{1}$.

\footnotetext{
${ }^{1}$ This has to be interpreted with caution as all economic costs may not be fully reported by all respondents (MSEs).
} 


\section{Percentage Share of Total Contribution}

Micro

Small

Medium and Large

Total Contribution, Small, $47.6,48 \%$
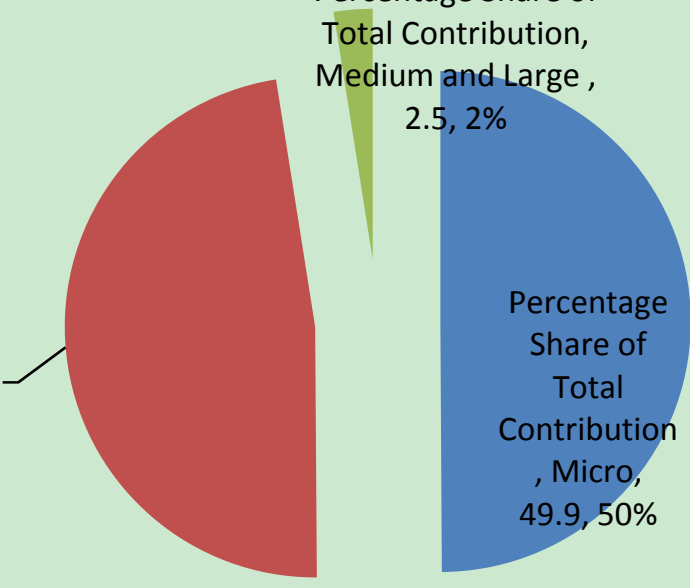

Figure 3. Relative of contribution of MSEs to regional GDP by size of the enterprise

Figure 3 shows that micro-enterprises have a share contribution of nearly $50 \%$ to the regional economy out of the total contribution made by micro, small, medium and large-scale enterprises. This is followed by a share of nearly $47 \%$ contribution by small enterprises. MSMEs have a share contribution of $97.5 \%$ to the regional economy out of the total contribution made by micro, small, medium and large-scale enterprises. One can infer from figure 3 that the share contribution of medium and large enterprises to the regional economy is $2.5 \%$.

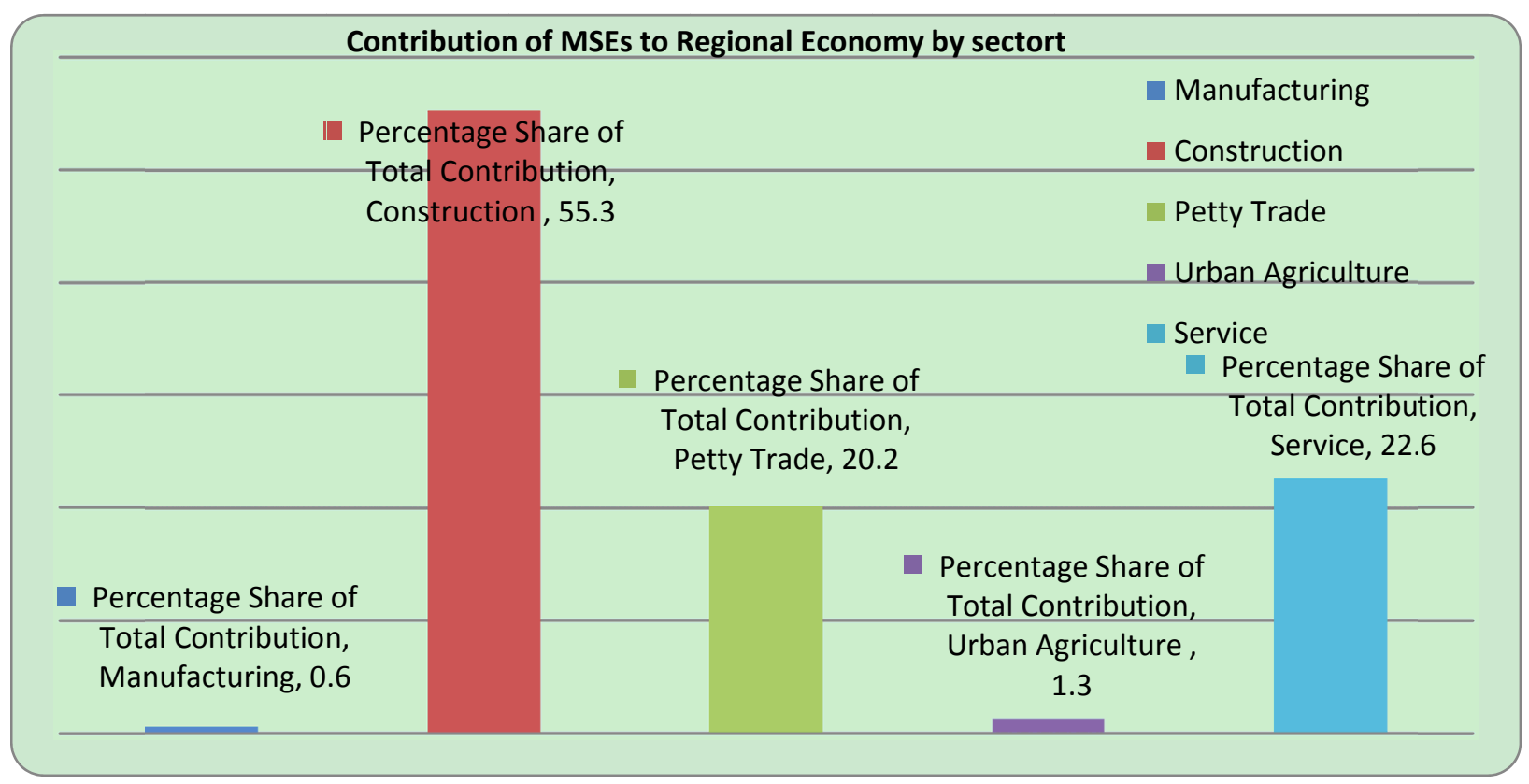

Figure 4. Contribution of MSEs to regional economy by sector

As observed in Figure 4, the sectoral contribution of MSMEs to the GDP is also interesting. Construction contributed the highest proportion (55.3 percent), followed by Service (22.6 percent) and petty trade (20.2) percent.

Figure 4 further shows that the contribution of the manufacturing sector to the regional economy has remained tiny. The share of this sector in regional total output is less than $1 \%$. This shows that the region needs to 
modernize this sector as it is a pillar of transformation from an agriculture-based economy to that of industry based and attain sustained economic growth.

Table 9. MSEMs over all contribution and per person engaged by firms

\begin{tabular}{ll}
\hline Size & Value-added per person engaged \\
\hline Micro & 12390.53 \\
Small & 21775.89 \\
Medium and Large & 42243.42 \\
\hline MSE Gross Contribution Referring to the Sample & \\
\hline Contribution Types & Gross contributions \\
\hline Gross contribution Per Person & 15943.42 \\
Gross employment creation & 10568 \\
Gross total asset contribution to the regional economy & 5600912 birrs \\
\hline
\end{tabular}

Referring to Table 9, micro-enterprises have the smallest contribution (12390) of value-added per person engaged as compared to small enterprises (21775.89). While medium and large enterprises have the highest contribution (42243.5) of value-added per person engaged. Considering MSMEs overall contribution, gross value added per person, gross employment creation, and gross total asset contribution to the regional economy are slightly above $15943.5,10,568$ and 5,600,912 million respectively.

In sum, we may conclude that this sector contributes significantly to the macro-economy of the region though disentangling the contribution of each subsector and presenting absolute values may not be plausible owing to poor baseline data in the region. As a final remark, the above figures display only the hard facts referring we make to the sample survey and no extrapolation. We arrive contribution per person at by computing the benefit accrued to MSEs Participants i.e. the value of final output-expenses (value of input + wage + rent + tax + utility and other expenses) divided by MSMEs participants.

Contribution per person engaged here is the contribution per person engaged in MSMEs either individually or in a group. One should remember we do not refer the employees as engaged persons because they are benefited from the value of output indirectly in terms of employment.

Table 10. Contribution per person engaged by sector

\begin{tabular}{ll}
\hline Size & Contribution per person engaged \\
\hline Manufacturing & 10605 \\
Construction & 28534.92 \\
Petty Trade & 10915.77 \\
Urban Agriculture & 3636.952 \\
Service & 14630.83 \\
Overall contribution Per Person & 15104.99 \\
\hline
\end{tabular}

Table 10 presents the value-added per person engaged in terms of a sector. Thus, the table shows that construction and service have respectively 28534.92 and 14630.83 contribution per person engaged. Urban agriculture and Petty trade contributed to 3636.952 and 10915.77 value-added per person engaged, respectively. The lowest value-added per person is created by the Manufacturing (10605) while the overall contribution per person engaged is 15104.99. This is an insightful result which has an interesting implication for policymakers. There is clear policy direction in the construction sector that states $40 \%$ of public construction should give $40 \%$ of public construction to MSMEs as sub-contractors. Thus, it could be the main reason for the boom observed in the construction sector. In fact, there has been a fast growth in the construction sector nationwide owing to persistent economic growth. Therefore, this could be the other cause of MSME boom in the construction sector as there is no exception in Tigray. 


\subsection{Means of Livelihood}

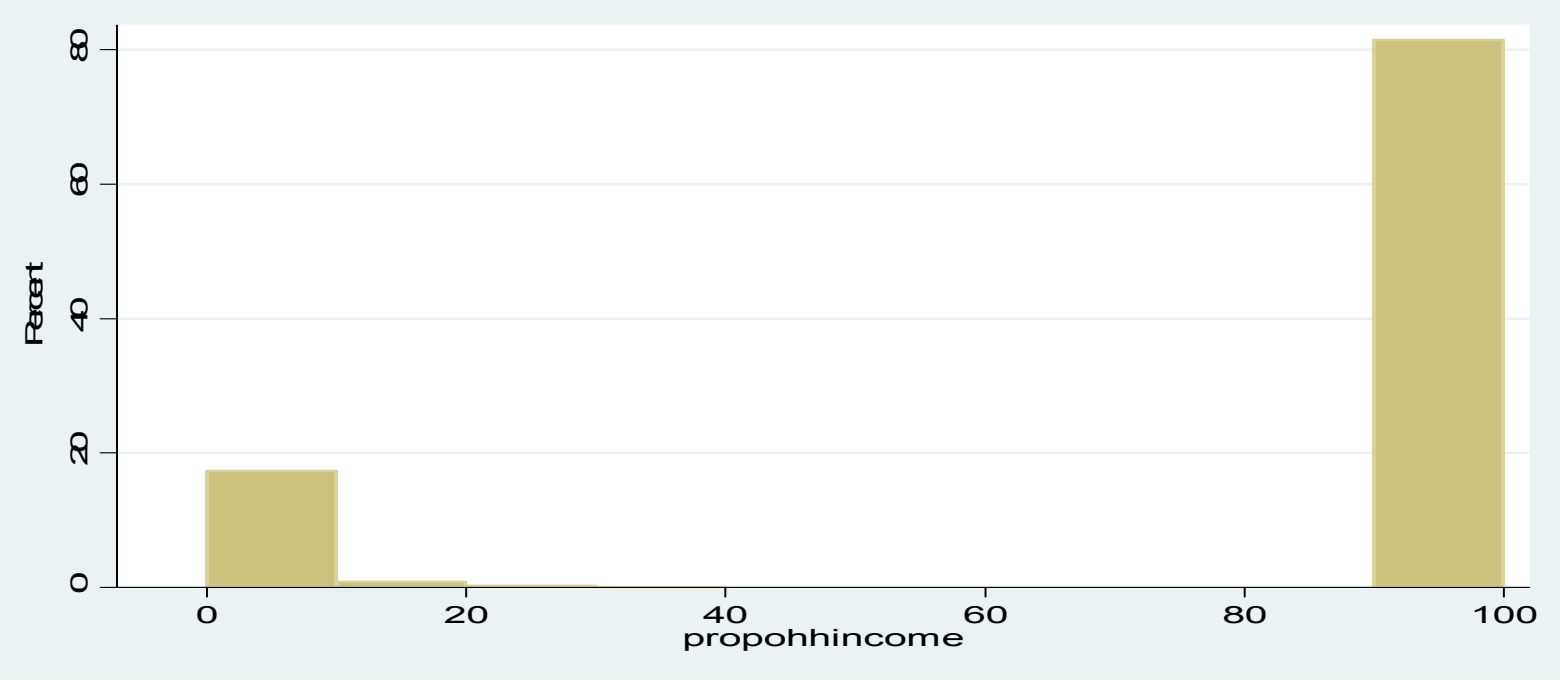

Figure 5. Proportion of Household Income from MSEs (\% of proprietors)

MSEs in the region seems to provide a larger fraction of household income. Overall, $80 \%$ of the surveyed MSMEs proprietors reported that their enterprise provided 100 percent of their family's total income. The higher dependence on MSEs in the region may reflect that many persons are engaged in this Micro and Small Enterprises.

\subsection{Women's Empowerment}
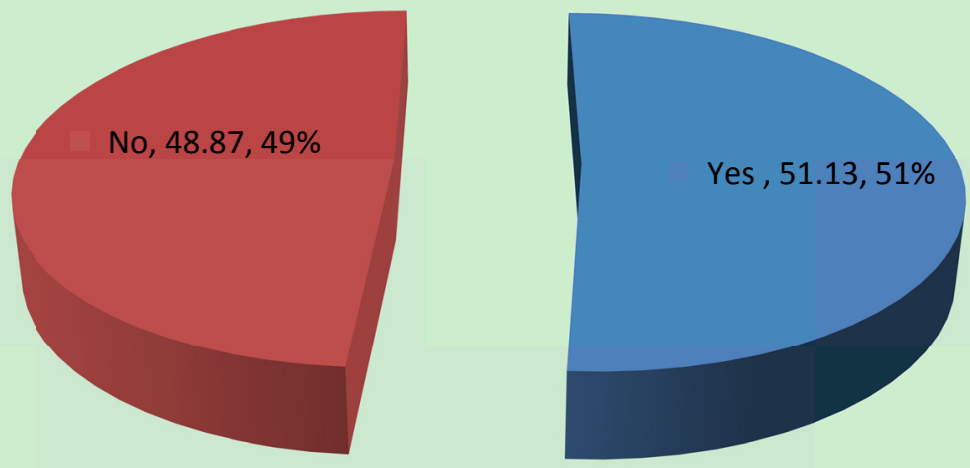

Figure 6. Permission for participation in MSEs

Since women entrepreneurs make up a significant portion of the MSE entrepreneurs in total (27.92\%), this study attempts to explore the benefits and barriers specific to women entrepreneurs. In this section, issues such as the need for permission to start an enterprise, perception of women entrepreneurs on specific issues - whether women entrepreneurs feel improvement and ultimately empowered is presented. 


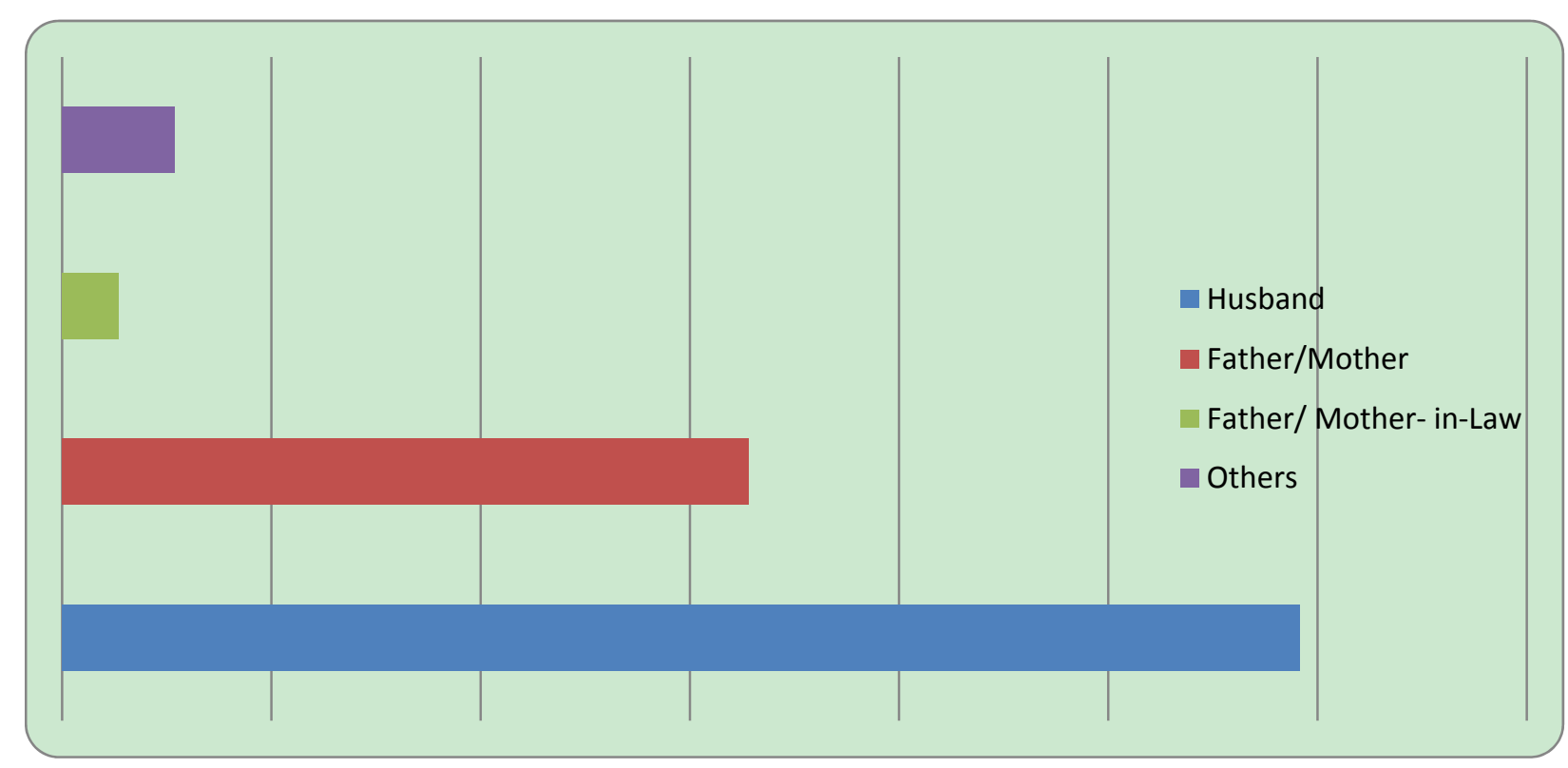

Figure 7. Permission for participation in MSEs

Women entrepreneurs face diverse responses from their families or relatives while attempting to start a business. While families strongly oppose women setting up an enterprise, others lent significant support. The pie chart in Figure 6 shows that $51.13 \%$ of the participant women entrepreneurs responded "No" to the question "Do you need any permission from your family to start a business?" Thus, the findings show that about half of the women entrepreneurs needed none permission from their families to start a business. The bar graph in Figure 6 shows that $64.10 \%$ and $30 \%$ of women entrepreneurs that needed to get permission from their families received it from their fathers and husband, respectively.

Table 11. Improvement of access to resources

\begin{tabular}{lll}
\hline Do you have equal access to? & Yes (\%) & No (\%) \\
\hline Nutritious food & 92.31 & 7.69 \\
Handling and spending money & 92.36 & 7.64 \\
Interpersonal communication & 94.81 & 5.19 \\
Education/training & 84.35 & 15.65 \\
Owned property & 59.55 & 40.45 \\
Able to get health care services for your family & 82.95 & \\
Overall & $\mathbf{8 4 . 4 0}$ & $\mathbf{1 5 . 6 0}$ \\
\hline
\end{tabular}

Table 11 shows that most women entrepreneurs (84.4\%) got overall improved access to resources such as food, money, health care services and education because of their engagement in business.

Table 12. Improvement in decision making

\begin{tabular}{lll}
\hline Decision & Yes (\%) & No (\%) \\
\hline Domestic decision & 92.08 & 7.92 \\
Financial decision & 91.40 & 8.60 \\
Child welfare decision & 93.64 & 6.36 \\
Reproductive health decision & 93.92 & 6.08 \\
Socio-political decision & 90.95 & \\
Overall & 92.40 & 7.60 \\
\hline
\end{tabular}


Table 12 presents the improvement in decision making about different issues of participant women entrepreneurs because of their engagement in MSMEs. The results in the table show that $92.40 \%$ of the participant women entrepreneurs have got an improvement in decision making about different issues because of their engagement in MSMEs.

Similarly, annex-1 show that a significant portion of women entrepreneurs fell improvement in gender perception, coping to household shocks, and overall change in income and living conditions. Hence, it can be safely concluded that taking part in micro and small business helps women to be better empowered better society with better health and living conditions.

\subsection{Reporting Results of Paired t-test on Total Asset and Employment Creation}

Table 13. Results of paired t-test on total asset and employment creation

\begin{tabular}{lllll}
\hline Variables & mean & S.E & t-ratio & observation \\
\hline Current assets (in 2002 E.C.) & 76457.8 & 3388.3 & & 1500 \\
Previous assets (in 2001 E.C.) & 60982 & 2534.8 & 7 & 1500 \\
Current employment (in 2002 E.C.) & 9.62 & .45 & & 1500 \\
Previous employment (in 2001 E.C.) & 9.2 & .39 & 2 & 1500 \\
\hline
\end{tabular}

We asked respondents to show their asset value and level of employment in 2002 E.C and 2001 E.C. We conduct the paired t-test to substantiate MSMEs growth in terms of asset accumulation and employment creation. The t-ratio for the first variable is significant at $1 \%$ level of significance which implies significant growth in MSMEs total assets in 2002 E.C. as compared to 2001 E.C. The second variable is significant at $5 \%$ level of significance likewise. This entails increasing employment in 2002 E.C. as compared with 2001 E.C. It also assists us to judge the consistency of the above results.

\subsection{MSEs Role in Poverty Reduction}

Table 14. Sample MSMEs poverty status

\begin{tabular}{lll}
\hline Poverty Measures & \multicolumn{2}{c}{ Estimation Results } \\
& Coefficients & S.E \\
\hline Headcount ratio & $\mathbf{3 8 . 6}$ & $\mathbf{0 . 0 1 3}$ \\
Poverty gap ratio & $\mathbf{1 8 . 8}$ & $\mathbf{0 . 0 0 8}$ \\
Squared poverty gap ratio & $\mathbf{1 2 \%}$ & $\mathbf{0 . 0 0 6}$ \\
\hline
\end{tabular}

Engagement in the MSME sector has brought income gain for the beneficiaries. With this context, we consider 1.25 dollar per day as a proxy to the poverty line (bumpy indicator). This is the worldwide indicator in poverty analysis. Besides, we consider households' average income of MSMEs' participants as a proxy for poverty indicator. This is obtained by dividing total income by the household members (family size). In this perspective, the MSMEs proportion of the poor below the anchor line is $38.6 \%$. While the poverty gap (income need to become non-poor) is $18.8 \%$. Finally, the depth of poverty is $12 \%$

The above poverty measures are close to national measures. Hence, MSEs have a significant contribution in poverty reduction.

\subsection{Determinants of Performance of MSMEs (Econometric Investigation)}

We conduct an econometric study to estimate the determinants of growth performance of the MSEs by running the following regression equation.

$$
\begin{aligned}
& \text { growth }=\beta_{1}+\beta_{2} \text { age }+\beta_{3 i} \text { Sectordummies }+\beta_{4} \text { linkage }+\beta_{5} \text { credit }+\beta_{6} \text { techno }+\beta_{7 i} \text { educationdummies }+ \\
& \beta_{8} \text { initialcapital }+\beta_{9} \text { gender }+\beta_{10} \text { training }
\end{aligned}
$$

Where growth is the measure of growth performance of MSEs in terms of sales growth ${ }^{2}$ and the explanatory

${ }^{2}$ Different authors use different dependent variables such as employment, sales productivity, value added growths 
variables are

I) It includes Age and MSE in the model to test the dependence of enterprise growth to its age and initial size.

II) Sector: it includes the sector dummies in the model to capture any effects of operating in the other sub-sectors compared with the manufacturing as the base sector.

III) Training: training affects performance

IV) We add access to credit into the model to observe the effects of financial resources. They take those who had access to credit as a reference group.

V) We added linkage which takes value one in case of having any kind of linkage with other enterprises since being related with other enterprises may have positive effects on growth in terms of business opportunities which could open new markets or increase productivity by sharing equipment or skilled personnel.

VI) Human Capital: The educational level variables EDU (i =1, 2, 3) are the human capital determinants. By incorporating these variables into the model, we would like to test whether the education level of the entrepreneur impacts the growth of the enterprise. A college education is a reference here.

VII) Technology a dummy that takes the value one if the entrepreneur stated that he/she uses the latest technology in the sector she/he is active.

VIII) Gender, a dummy taking the value one if the entrepreneur is male.

\section{Estimation Result of Employment Growth Determinants}

Applying linear regression to estimate the parameters of the model, both Breusch-Pagan and White tests for heteroscedasticity-rejected homoscedasticity. As a remedy, we have computed White standard errors and the results we report the results in Table 15.

As seen in Table 15, the conclusion reads that initial capital is inversely related to growth. Specifically, initial capital is a significant variable; MSEs with higher initial capital has significantly lowered growth rates than MSEs with a lower initial capital. Putting differently, other factors being equal, MSEs that started a business with higher capital have lower average growth rates than MSEs that started with lower capital levels. Besides, MSEs with lack of access to credit grow less compared with MSEs with credit access... Demand conditions as showed by sales growth is also a significant factor. Further, the technology dummy shows that MSEs that use modern technology grow faster. Two things are worth nothing from table 15. First, as shown by the training dummy, MSEs with trained owners have higher growth than those without training do. This finding has an important policy implication. Second, the linkage has a significant impact on growth. Holding other factors constant, MSEs that have linkage have higher average growth rates. Our findings are consistent with the existing empirical literature (see the findings of Liedholm and Mead (1993), McPherson (1996), Mulu (2007) and Ozar (2003)).

Table 15. Regression results

\begin{tabular}{lll}
\hline Dependent Variable: Employment growth & & \\
Independent Variables & Coef. & Std. Err. \\
\hline Initial capita & $-.0920 * * *$ & .0279 \\
Firm age & -.0210 & .0598 \\
Credit & $-.2887 * * *$ & .1020 \\
Linkage & $.2795^{* *}$ & .1165 \\
Construction & -.2650 & .2265 \\
Sales growth & $.3620^{* *}$ & .1574 \\
Petty trade & $.2906 * *$ & .1657 \\
\hline Urban agriculture & $.2763 *$ & .2027 \\
Service & -.0301 & .2043 \\
High School & -.0323 & .2454 \\
Elementary & -.4341 & .5379 \\
\hline
\end{tabular}




\begin{tabular}{lll}
\hline Technology & $.1726^{*}$ & .0134 \\
Taken part &. $.4387^{* * * *}$ & .1663 \\
Female & -.2914 & .2027 \\
Age of Owner & -.2061 & .2768 \\
Constant & .1 .305 & 1.272 \\
Observations: & $\mathbf{5 0 0}$ & \\
R-Squared & $\mathbf{0 . 5 2}$ \\
Adjusted R & \\
F-statistic & $\mathbf{0 . 5 1}$ & \\
& $\mathbf{3 2 . 7 7 ^ { * * * }}$ \\
\hline
\end{tabular}

Notes: one, two, and three asterisks denote significance at 10, 5, and 1 percent levels respectively

\section{Market Linkage and Determinants of MSMEs' Growth and Sustainability}

In this section, we shall present a brief description of various types of linkages such as (sectoral and institutional linkages), industrial growth-related issues, training and business development service (BDS), determinants of MSMEs' growth and sustainability and major barriers to MSMEs' development.

This study intends not only to provide a conceptual overview of determinants of MSMEs' survival critical to the arguments in a present discourse of this sector but also it synthesizes the concept of market linkage and prospects of this sector.

The concept of MSMEs' dynamics is becoming a wrestling ground for many experts in this area. MSMEs are in a constant state of fluctuation. During any period, new firms are being created (new starts, or enterprise births), while others are closing; some existing firms are expanding, and others are contracting in size. However, the significance of most of these changes is overlooked by a limited focus on the aggregate changes in SMMEs' performance indicators. For an economy that is dominated by small enterprises like Ethiopia, understanding the factors influencing the enterprises' life cycle is critical for facilitating the entrance of larger enterprises into the market.

Also, several studies underline that the poor's priority of security over economic growth is a neglected aspect in considering MSMEs as antipoverty interventions.

Many kinds of research cast serious doubt on the survivalist camp of MSMEs and claim that enterprises enter the same market all the time, which results in over-trading and involution growth. They go on castigating the generic technical skills and business training in low-value-added activities while working with survivalist or micro-enterprises, existing or new businesses. Creating new survivalist enterprises to compete with existing enterprises in the same sectors and markets; rather than generating income and employment for the poor, it contributes to the insecurity of existing entrepreneurs. If income is insecure, it is not sustainable (Von Broembsen, 2003).

They contend, if a survivalist enterprise generates less income than the poverty line and the income generated secured is insecure, then the organic growth of survivalist enterprises may make up a survival strategy but does not ease the abject poverty and should not be pursued as a good strategy for MSMEs.

\subsection{MSMEs Linkages}

The data collected from the survey contained information on the linkages among MSMEs, including their operating environment and enterprise networks. The questions on linkages included the contacts they maintained with different enterprises. These concerned linkages with enterprises of various size and activities, linkages with other enterprises in the same line of business, or different lines of business, with smaller or larger enterprises, linkages with public institutions. We also asked enterprises whether they sold their products directly to consumers for final consumption, or for further production.

\subsubsection{Institutional Linkage}


Table 16. Institutional Linkage

\begin{tabular}{llll}
\hline Linkage with various partners & \multicolumn{2}{l}{ Level of linkage (in percentage) } \\
& No linkage & Moderate linkage & Highly linked \\
\hline Public institutions of the region & 59.79 & 14.25 & 25.96 \\
Regional colleges/TVETs/ & 67.77 & 12.69 & 19.54 \\
Universities and research centers & 83.95 & 9.28 & 6.77 \\
Other companies in the region (suppliers, customers, partners etc.) & 50.79 & 18.8 & 30.41 \\
Technology transfer centers & 74.76 & 10.69 & 14.55 \\
Companies outside the region & 88.36 & 6.69 & 4.95 \\
NGOs & 81.59 & 8.17 & 10.24 \\
\hline
\end{tabular}

Table 16 shows the linkage of MSMEs with various partners with varying levels of linkages expressed in terms of percentage. The table shows that most of the enterprises have low linkage with various partners. Over $83 \%$ of the participant MSEs has no linkage with universities and research centres; a similar proportion (88\%) of them has no linkage with companies outside the region; $81 \%$ of the participant MSEs has no linkage with NGOs. A relatively considerable proportion of MSEs (30\%) is highly linked with other companies in the region (suppliers, customers, partners etc.). Next, to this partner, public institutions of Tigray Region are highly linked with $25.96 \%$ of the participant MSMEs. A close proportion to $20 \%$ of the participant MSEs is also highly linked with Regional colleges/TVETs/.

\subsubsection{Sectoral Linkage}

Table 17. Sectoral linkage

\begin{tabular}{lll}
\hline & \multicolumn{2}{l}{ Do you have a linkage with other enterprises? } \\
\hline Sector & Yes & No \\
\hline Manufacturing & 26.52 & 73.48 \\
Construction & 37.97 & 62.03 \\
Trade & 14.29 & 85.71 \\
Urban Agriculture & 19.88 & 80.12 \\
Service & 23.31 & 76.70 \\
Total & $\mathbf{2 3 . 2 9}$ & $\mathbf{7 6 . 7 1}$ \\
\hline
\end{tabular}

The survey generated information regarding the linkage between MSMEs and other enterprises, similar enterprises and industries which shows sectorial linkage. As presented in Table 17, out MSEs a proportion of 23\% has linkage with other enterprises operating either in similar or dissimilar business fields, while $77 \%$ of the enterprises have no linkage at all.

From this, a larger proportion accounting $37.97 \%$ and a similar proportion to that $(26.52 \%)$ covers by construction and manufacturing sectors, respectively. Trade accounts $14.29 \%$ is the least linked enterprise. However, the majority $(76.71 \%)$ of the participant MSMEs have no established linkage with other enterprises and industries. From this one can infer that since the MSEs in Tigray have very limited linkage with each other and other industries they are less competitive and sluggish to graduate into lead enterprises. They are weak in providing supplies or purchasing from enterprises to make other products or services.

As the information got from a majority of respondents, the most common reasons for not considering linkage are like lack of awareness on the importance of linkage, the need to be independent, and fear does not meet obligations. 


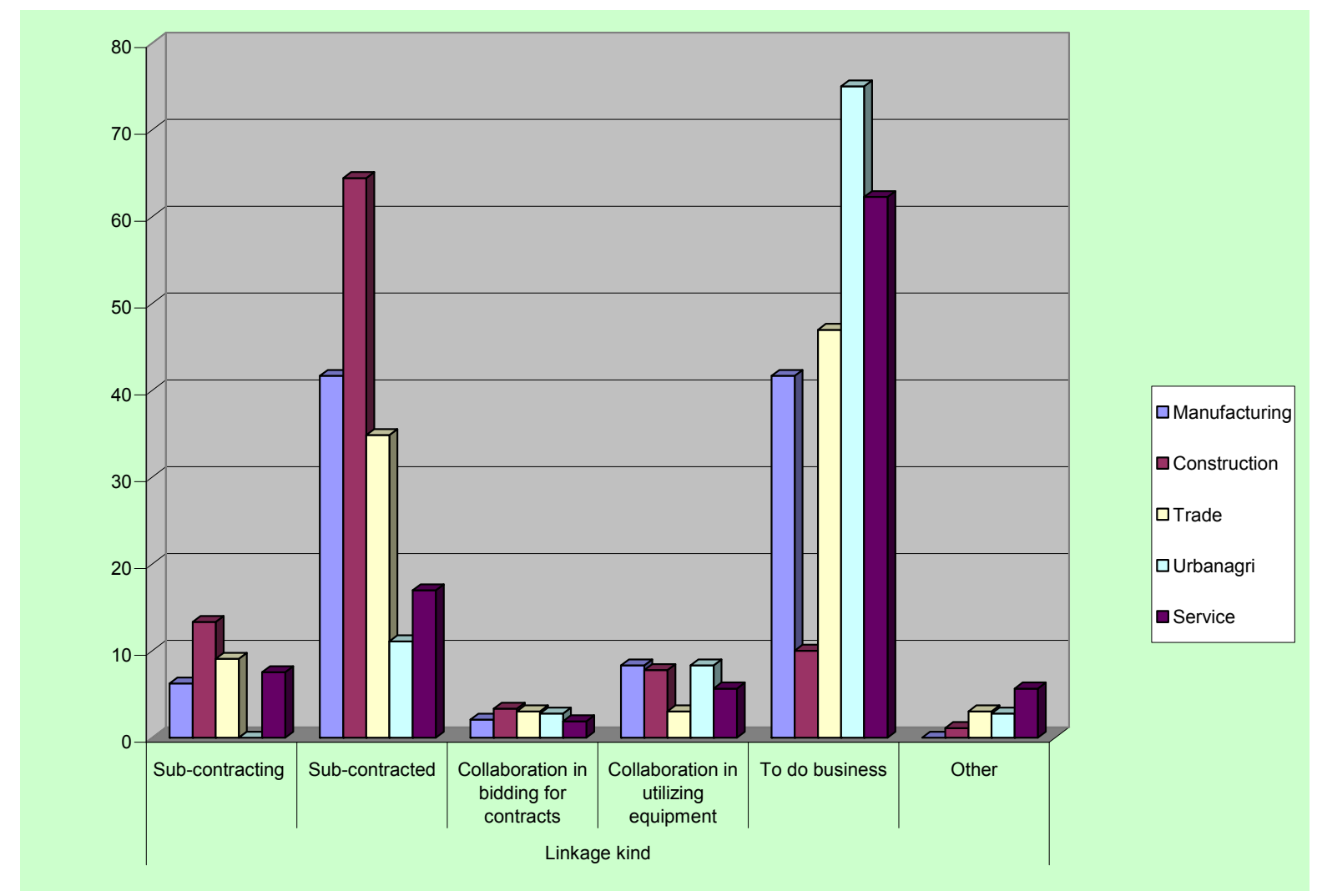

Figure 8. Linkage kind

It also raised for those who have a linkage, it also raised the question "what is the linkage?" $40.96 \%$ of the enterprises have a linkage to do business, a very similar proportion, $38.91 \%$ of the enterprises have sub-contracted kind of linkage. Similarly, only $8.53 \%$ of the enterprises have sub-contracting linkage kind, while $2.73 \%$ and $6.48 \%$ of the enterprises have established a linkage for collaboration in bidding for contracts and in using pieces of equipment, respectively. Finally, $2.39 \%$ of the enterprises have a kind of linkage other than the above mentioned once. Among those who have a linkage to do business and subcontracted kind of linkage, they are from urban agriculture and construction sectors respectively (Figure 8).

\subsubsection{Linkage and Innovation Policies}

As inferred from Table 18, on average more than half of the sample enterprises $(58.12 \%)$ responded that public institutions of the region do not provide enough help for MSMEs in business startup, creating market opportunities, promoting networking/internal linkage, human resource development and giving guidance. On average $59.08 \%$ of the MSMEs agree that the public institutions of the region do not promote innovation atmosphere and Universities, TVETs and research centers are very weak in scaling up and scaling out research findings related to MSMEs. Besides, $61.38 \%$ of the respondents agree that public institutions of the region have very weak support in developing clusters while $62.35 \%$ of the MSEs agreed that government institutions do not encourage MSEs by purchasing innovative products. 
Table 18. Linkage and innovation policies

\begin{tabular}{|c|c|c|c|c|}
\hline \multicolumn{2}{|c|}{ Linkage and Innovation Policies } & \multicolumn{3}{|c|}{ Rating (in percentage) } \\
\hline & & Disagree & Undecided & Agree \\
\hline \multicolumn{5}{|c|}{ A. Innovation } \\
\hline$\checkmark$ & Public institutions of the region provide sufficient help in the starting stage of new business & 57.52 & 10.43 & 32.05 \\
\hline$\checkmark$ & Public institutions of the region provide help in identifying and developing market opportunities & 58.47 & 12.33 & 29.2 \\
\hline$\checkmark$ & Public institutions of the region provide support in networking & 62.88 & 12.2 & 24.93 \\
\hline$\checkmark$ & Public institutions of the region promote internal linkages & 62.51 & 13.15 & 24.34 \\
\hline$\checkmark$ & Public institutions of the region support developing human resources/short-term pieces of training & 50.99 & 11.62 & 37.39 \\
\hline$\checkmark$ & Public institutions of the region provide guidance when needed & 56.28 & 9.8 & 33.92 \\
\hline \multicolumn{5}{|c|}{ B. Linkage } \\
\hline$\checkmark$ & Regulation and educational policies shape innovation performance & 52.19 & 12.33 & 35.48 \\
\hline$\checkmark$ & Innovation policies and related support are strongly technology-driven & 55.04 & 13.28 & 31.68 \\
\hline$\checkmark$ & Public institutions of the region provide support in developing clusters & 61.38 & 13.2 & 25.42 \\
\hline$\checkmark$ & Public institutions of the region promote an innovation-favourable atmosphere & 58.51 & 13.02 & 28.48 \\
\hline$\checkmark$ & Public institutions of the region support innovating industries/businesses & 60.92 & 11.2 & 27.88 \\
\hline$\checkmark$ & Public institutions of the region play roles in scaling up and scaling out research findings & 63.14 & 14.16 & 22.7 \\
\hline$\checkmark$ & Government institutions purchase innovative products & 62.35 & 15.32 & 22.33 \\
\hline
\end{tabular}

\subsubsection{Sources of Innovation}

Figure 9 shows that the largest share for innovation source our customers which accounts to $30.34 \%$. Besides, $24.92 \%$ of the innovations come from higher institutions especially TVETs. The figure shows that systematic in-house R\&D and innovation process, which encourages indigenous innovation, accounts only $16.2 \% ; 16.97 \%$ and $11.75 \%$ from suppliers and skilled employees of the firm, respectively.

From the results, it is possible to deduce that most of the MSMEs produce new products or change them based on customers' preference. They have a limited initiative to add value to products or designing new products through systematic in-house innovation and R\&D regardless of customer dependence. The trend with higher institutions especially TVETs is relatively good and the results inform concerned bodies to diversify the linkage by involving Universities, TVETs and research centres in innovation projects at large scale.

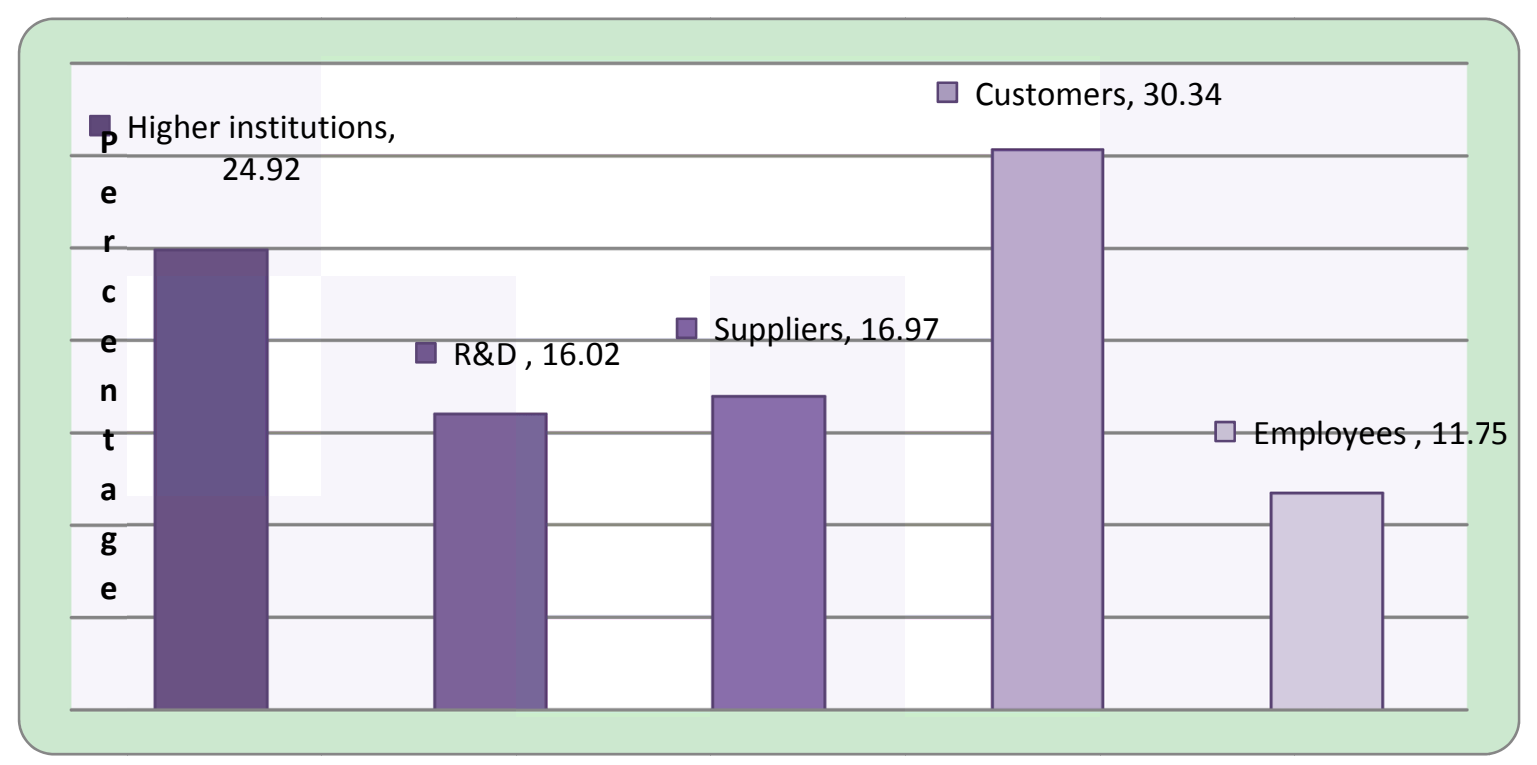

Figure 9. Source of innovation 


\subsubsection{Industrial Growth}

The survey generated information regarding the industrial growth of participant MSMEs. We try to describe MSMEs growth in terms of the destination of the product, levels of employment they created, raw materials they consumed, and level of sales revenue they generated.

When there is a high proportion of MSMEs product for further production, we expect their contribution to industrial growth to be high. It involves as seen from Figure 10, on average $76.77 \%$ of MSMEs in producing products for final consumption while $12.33 \%$ of them produce for further production and the remaining $10.90 \%$ for both production and final consumption purpose. Sector-wise, the construction sector contributes $23.67 \%$ in producing products for further production. The services sector contributes $6.61 \%$ of products for further production. From this, we can infer that the forward marketing linkage MSEs with industries is weak.

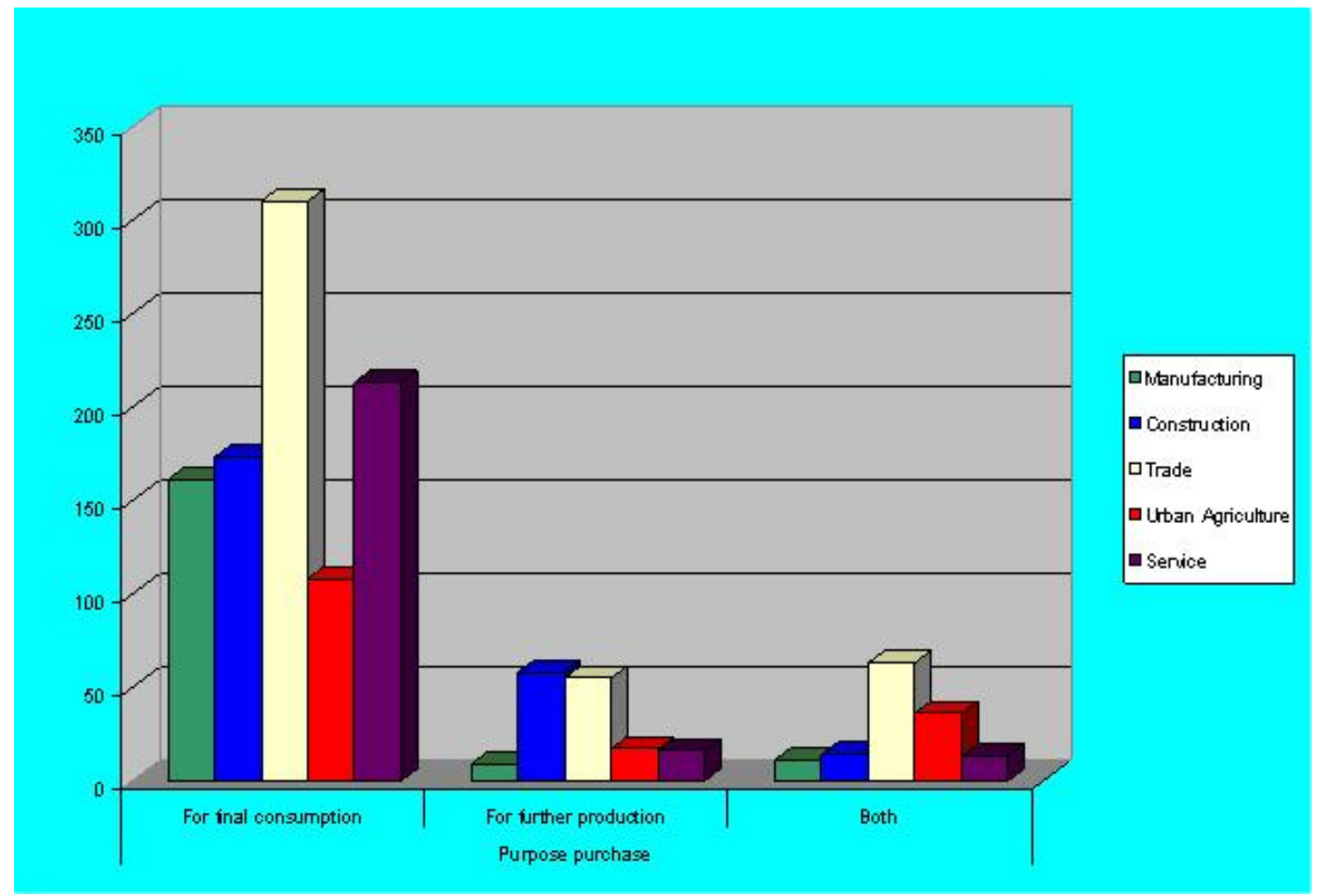

Figure 10. Purpose of the produced product

Table 19. Results of paired t-test on employment creation, total inputs and sales revenue generated

\begin{tabular}{llll}
\hline Variables & Mean & S.E & t-ratio \\
\hline Current input (in 2002 E.C.) & 70552.82 & 10722.94 & 702 \\
Previous input (in 2001 E.C.) & 59253.38 & 9801.86 & 702 \\
Current sales revenue (in 2002 E.C.) & 71898.58 & 6571.70 & 7 \\
Previous sales revenue (in 2001 E.C.) & 59095.06 & 6285.70 & 702 \\
Current employment (in 2002 E.C.) & 9.62 & .45 & 1500 \\
Previous employment (in 2001 E.C.) & 9.2 & .39 & 2 \\
\hline
\end{tabular}

We asked sample MSMEs to show their employment level, input value and level of sales in 2011 (current) and 2010 (previous). We conduct the paired t-test to show MSMEs contribution for industrial growth in terms of employment level, sales revenue generated, and raw materials consumed. As stated in Table 19 above, the t-ratio for the first and second variables is significant at $1 \%$ level of significance which implies significant growth in raw materials consumption and sales revenue generation in 2011 as compared with 2010 the third variable is significant at 5\% level of significance. This entails increasing in employment creation in 2011 as compared with 2010 
Even though MSMEs in the region are limitedly engaged in producing products for further production (supply for other industries), they contribute significantly for industrial growth by creating employment opportunities, generating sales and consuming more raw materials.

\subsubsection{Sources of Raw Material}

Information collected about a source of raw materials for the participant MSMEs is displayed in Figure 11. A large proportion, $75.72 \%$, of the participant MSMEs rely on raw materials got from the region. It is worth mentioning that, $15 \%$ of the participants MSMEs get their raw materials from other regions. In contrast, a small fraction, 9.28\%, of the participant MSMEs rely on imported raw materials. Besides, discussions with focal persons show that though most of the raw materials are obtained from the Tigray region, it has long distribution channels which contributes to the inflation of raw material price. The increase in the cost of raw materials enforces MSEs to reduce their profit margin.

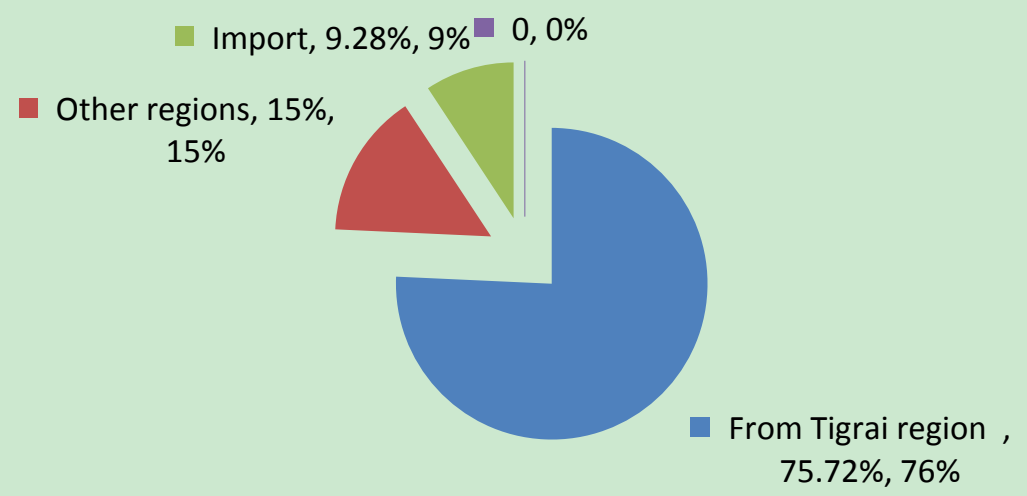

Figure 11. Source of raw material

\subsubsection{BDS and Training}

As shown in Figure 12, out of the total sample of MSMEs only 322 enterprises have got BDS while a majority of them (1093) have not got BDS so far. As per the discussions held with focal persons, though there are several privates and government BDS providing institutions in the region there is a gap in organising them to deliver a proper or demand based BDS.

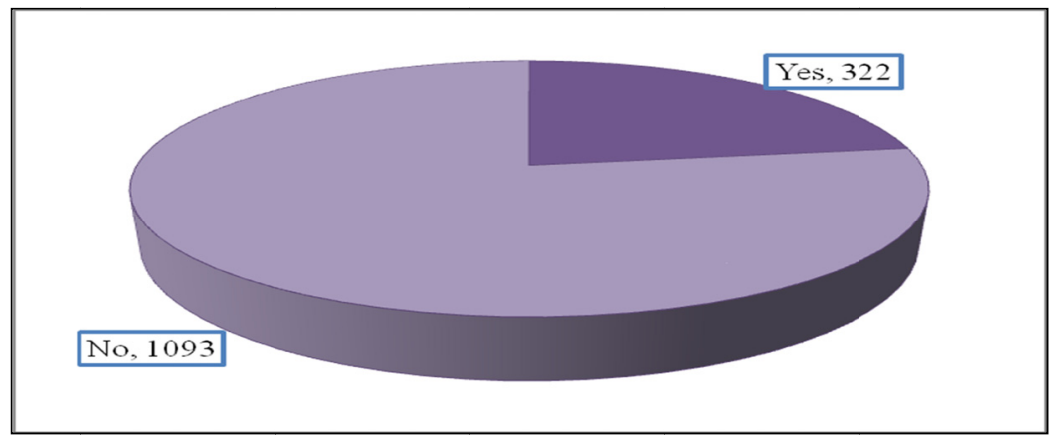

Figure 12. Provisions of BDS

According to Vandenberg (2006), enterprises rely on a range of business development services (BDS) to understand markets, develop products, refine production, and improve management. BDS can raise MSEs productivity by addressing key constraints such as low skill levels, weak management, low level of technology, weak linkages and support systems.

Figure 13 shows that $60 \%$ of the participant entrepreneurs need training in business planning and running, especially on bookkeeping. However, $40 \%$ of the participant entrepreneurs answered "No" to the question "Do you need training?" As the information got from a majority of respondents, the most common reasons for no need to take part in training are like lack of awareness on the importance of training, not willing to waste time on training/ schedule of training/. 


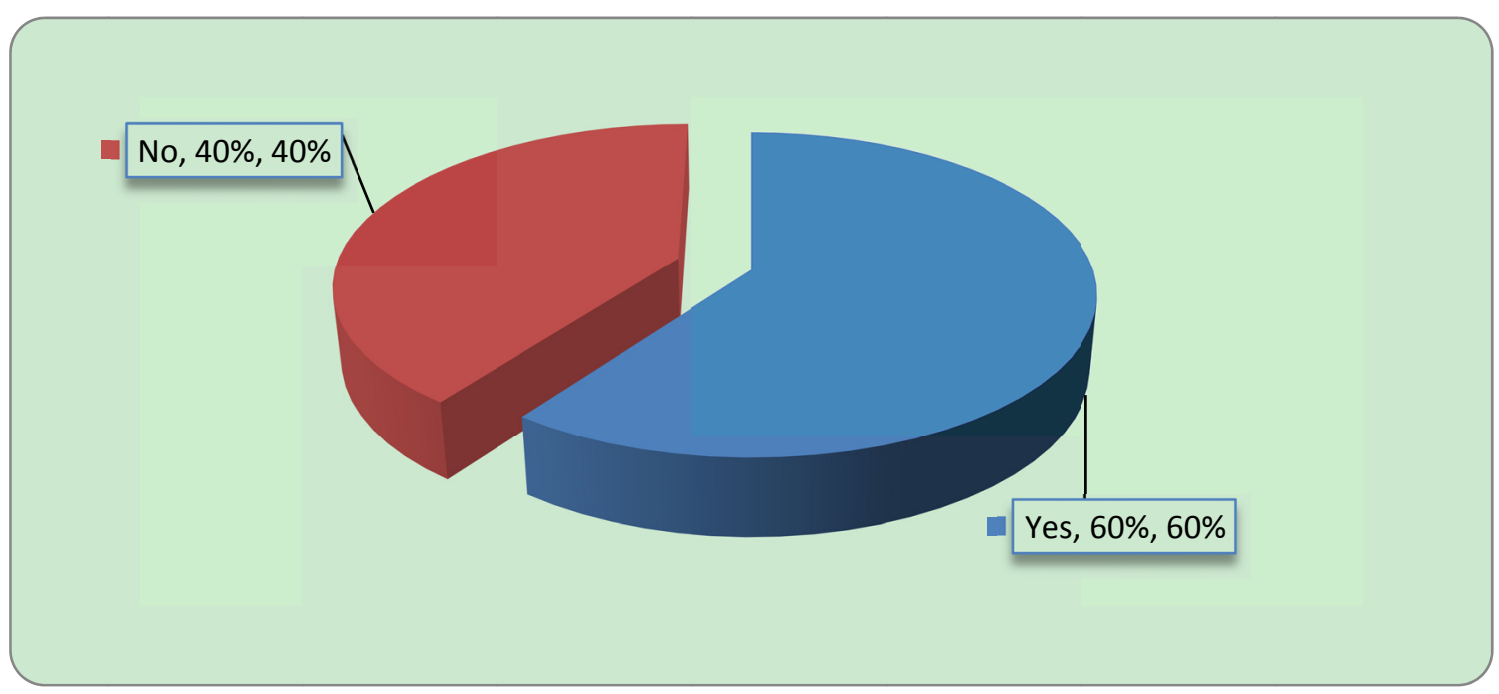

Figure 13. Training participation

Training is transferring information and knowledge to employers/employees, equipping employers to translate that information and knowledge into practice to enhance organizational effectiveness and productivity, and the quality of the management. Given today's business climate and the exponential growth in a technology with its effect on the economy and society at large, the need for training is more pronounced than ever. Training helps increase job satisfaction and morale, increase motivation, increased efficiency in process, resulting in financial gain, increased capacity to adopt new technologies and methods, and increased innovation in strategies and products (McClelland, 2002).

As stated in Figure 14, we also asked respondents to rate the main problems with the training they received. More than half of the respondents of the survey reported that the on-off nature (irregularity) of offered pieces of training is the most serious problem. $35.50 \%$ of the informants responded that lack of help at a workplace for implementing the training offered is the next most pressing problem. Similarly, a tiny proportion of the respondents, $4.85 \%$ and $8.50 \%$ have reported fitness to the purpose (not customized) and low outreach problems respectively as the main problems of the training they received. From the aforementioned information, one can safely infer that, even though different pieces of training are organized and offered by different organs, participants do not implement effectively because there are very limited follow-up and help from the respective organ.

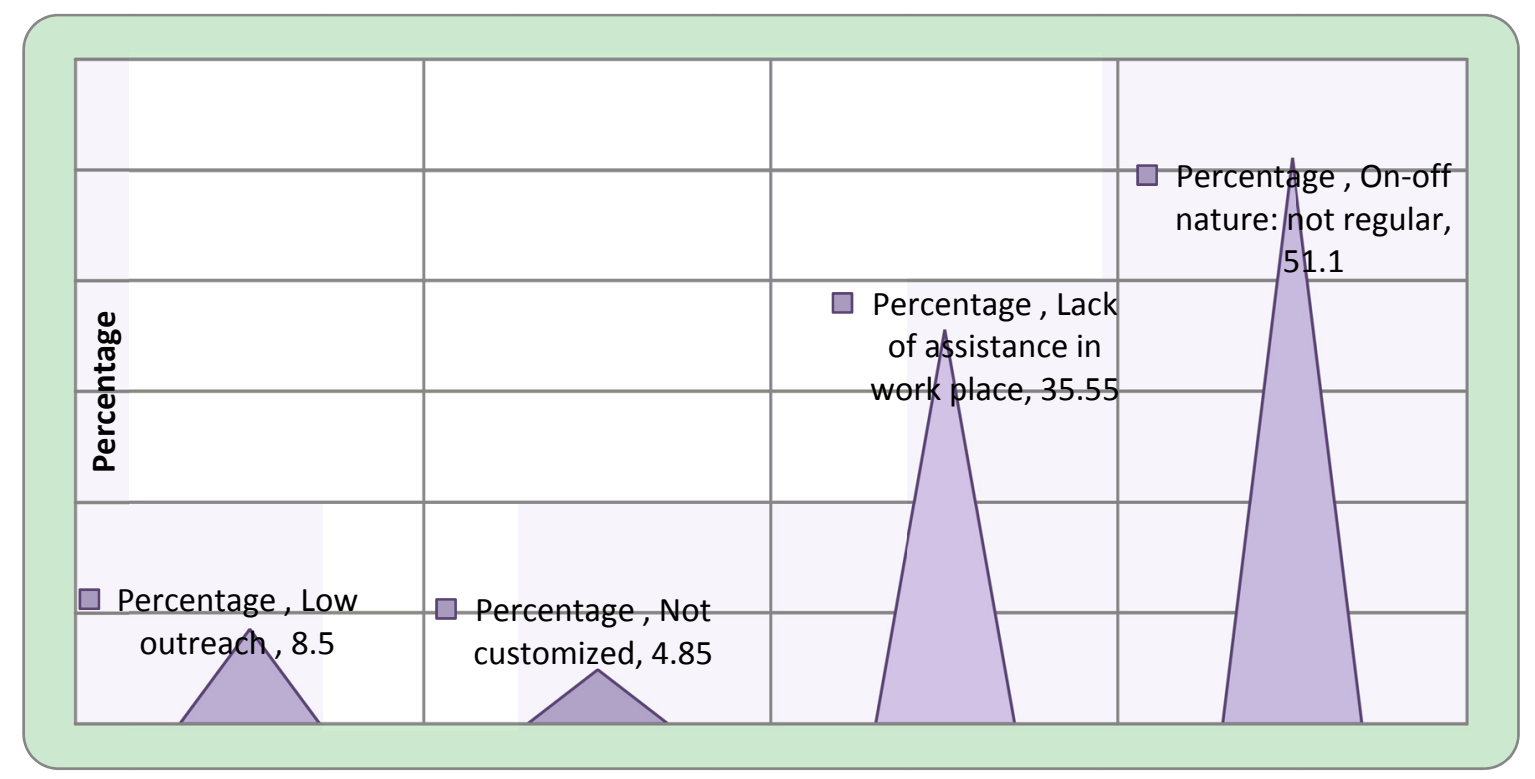

Figure 14. Training problems 


\subsection{MSMEs Growth and Sustainability Determinants}

Addressing factors that determine the growth and sustainability of MSMEs is among the objectives of the study. Some of these are limited market access, lack of need-based training, inflation, lack of credit access, procedural difficulties in business startup, access to productive resources, and bad leadership.

\subsubsection{Determinants of MSMEs' Growth and Sustainability}

We can view the theoretical deliberation on the link between business constraint and the growth potential of MSEs from diverse angles. Business constraints not only limit physical capital accumulation but also a firm's capability to embark on its daily operations as they reduce its internal financing and its capacity to make proper business decisions. Likewise, they may break off a firm's business operations and therefore slow down its growth.

This section overviews the theoretical and empirical MSEs' growth and sustainability determinants from national and international perspectives.

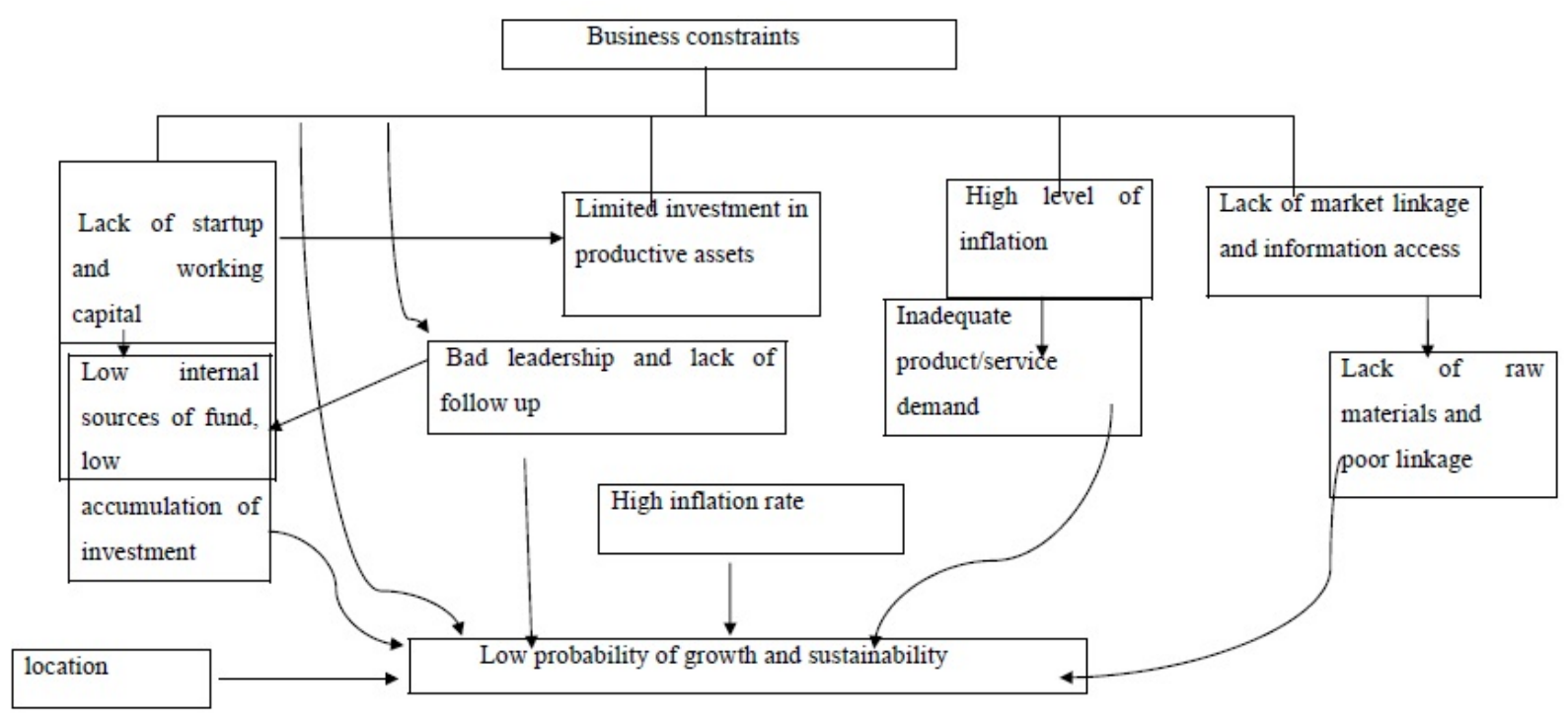

Figure 15. Conceptual framework of MSMEs constraints

\subsubsection{Results and Discussions}

While investigating the determinant factors of MSMEs' growth and sustainability using cross-section data and the respective methodologies discussed previously; first we succinctly describe the constraints; next, we present and discuss the econometric results of growth and sustainability determinant factors and the sample mean tests. Moving on, we shed light on external determinant factors we observed in a focus group discussion with respective MSMEs official.

\subsubsection{MSMEs' Survival Determinants: Reporting Estimation Survey Results}

In this part, we present, a brief description and definition of determinants of MSMEs' growth and sustainability explanatory variables given in Table 20. This table presents a definition and descriptive statistics of the independent variables for the total sample, the sample with cooperatives and for those without. When we conducted this survey in March 2011, we reached 1500 MSMEs, of which 753 were cooperatives and the rest non-cooperatives. Of the total, 548 are female owned cooperatives. Of the females, 126 are cooperatives.

Table 20 presents a succinct description and definition of MSMEs' growth and sustainability determinant variables of all respondents used in the logit regression. Considering demographic characteristics, it shows that the respondents are 35 years old on average and the average household size is four. In terms of education, $65 \%$ of the participant MSEs' member household heads are literate.

On an average MSEs' current average capital is 19232. Considering employment creation, on average they use six people. MSMEs establishment preference (individual or group), MSMEs access to the credit facility and Access to need-based training and business development service are other explanatory variables significant at 5\% 
and $1 \%$ level of significance.

\subsubsection{Summary Statistics and Descriptions of Variables}

Table 20. Descriptive statistics and definitions of MSMEs' growth and sustainability determinant variables

\begin{tabular}{|c|c|c|c|c|}
\hline \multirow{2}{*}{$\begin{array}{l}\text { Brief description of variables } \\
\text { Definitions }\end{array}$} & \multicolumn{4}{|c|}{ Sample survey } \\
\hline & Obs. & Mean & $\underline{\text { S.D }}$ & $\underline{\mathrm{t} \text {-test }}$ \\
\hline Temporary business closure; dummy(1=yes) & 323 & 1 & 0 & - \\
\hline Age of MSE owner/manager & 1436 & 35 & 11 & $113.5^{* * *}$ \\
\hline Size of household members & 1436 & 4 & 2.3 & $70.92 * * *$ \\
\hline The education level of the household head & 1436 & .65 & 3 & $83 * *$ \\
\hline Sex of MSE owner/manager $\quad(1=$ male $)$ & 412 & .71 & .45 & $59.7 * * *$ \\
\hline MSEs establishment preference(1=group) & 753 & .52 & .50 & $39.7 * * *$ \\
\hline MSEs access to credit facility (1=yes) & 961 & .363 & .481 & $2.80 * *$ \\
\hline Access to need-based training and business development service $(1=$ yes $)$ & 472 & .31 & .46 & $26.2 * * *$ \\
\hline
\end{tabular}

$* * *=$ significant at $1 \%$ level; $* *=$ significant at $5 \%$ level; and * = significant at $10 \%$ level

Sources: Authors'calculation from MSMEs survey

Having identified these explanatory variables, the next logical step is estimating the logistic regression using these independent variables.

\subsubsection{Results of Logistic Regressions MSMEs' Growth and Sustainability Determinants}

Estimation results of logistic regression in Table 21 are insightful in the case for the entire MSMEs' growth and sustainability determinants. The dependent variable is whether a certain MSME has experienced closed temporarily because of various reasons. This is a typical example of binary response models. In fact, our core aim is to explore the determinants of MSMEs' growth and sustainability. In order to appropriately address the issues, we asked participant MSMEs if they experienced temporarily close. The presumption is that identifying the causes for temporarily close may help us identify the causes of MSMEs' growth and continuity. We strongly believe that not only this issue can better be addressed using longitudinal data via collecting data on the previously in operation yet exited firms but also by collecting data on already exited firms in case of the sample survey. The former is the better as the latter involves a difficulty of locating previously in operation but now exited firms. Thus, the best remedy for the said issue in cross-sectional data analysis is to set questions that help to investigate the causes of a temporary shutdown and make a logical deduction about determinants of firm dynamics.

To explain the coefficient estimation results, MSEs owned/managed by man are more likely to temporarily stop operation owing to various reasons, which is significant at a $5 \%$ significance level. This is consistent with the arguments of (Mitra, 2002; Mitra \& Pingali, 2000).

Table 21. Logistic estimates for determinants of MSEs' growth and sustainability

\begin{tabular}{llll}
\hline Participation in micro-finance & Coefficients & $\mathbf{Z}$ & Marginal effects after probit (mfx) \\
\hline Variables & & & \\
Sex of MSE owner/manager & $.364^{* *}$ & 2.28 & .0354 \\
MSEs establishment preference & -.092 & -1.62 & -.014 \\
MSEs access to a credit facility & $.356^{* *}$ & 2.28 & .057 \\
Access to need-based training and business development service(BDS) & $0.852^{* *}$ & 2.36 & .730 \\
Current capital per MSE & $.083^{*}$ & 1.85 & .013 \\
Current employment per MSE & .011 & 1.29 & .0017 \\
constants & $-1.497^{* *}$ & -2.87 & - \\
\hline
\end{tabular}


Number of obs $=1427 \quad \mathrm{y}=\operatorname{Pr}($ participation in $\mathrm{mf})$ (predict)

LR $\operatorname{ch} 2(12)=21.7 * * \quad=.771$

Prob $>$ chi $2=0.0012$

Log likelihood $=-570.2 \quad$ Pseudo R2 $=0.1490$

$* * *=$ significant at $1 \%$ level; $* *=$ significant at $5 \%$ level; and $*=$ significant at $10 \%$ level.

The coefficient estimates of MSMEs' access to credit facility is significant at 5\% significance level and the direct association is not only consistent with constraints ranked by respondents but also with the findings of (Akoten, Sawada, \& Otsuka, 2006). It means MSMEs with access to credit facility are more likely to sustain their business. Similarly, access to need based training and business development service (BDS) and current capital of MSMEs are significant at $10 \%$ and $5 \%$ significance level, respectively. This is consistent with results of (Mason, 1998; Gebrehiwot and Amaha, 2003) and (Field, Hitchins, \& Bear, 2000; Gbson, Hitchins \& Bear, 2001; Lusby \& Panlibuton, 2002). The implication is that MSMEs with access to need based training (BDS) are more likely to survive and grow and the vice versa. We do not include other variables considered as independent but insignificant as part of the report.

We can comprehend the estimation results of the marginal coefficient as a unit increase in access to credit facility decreases the exit of enterprises by $5.7 \%$, other things being the same.

In a similar fashion, a unit increase in BDS and need-based training reduces enterprises MSMEs death by $73 \%$, keeping other things constant. We may conclude from the results that access to credit facilities and need-based training are key determinants of MSMEs survival. As a result, MSEs is drafting MSMEs policies and strategies because of attention ought to be given to these factors.

\subsubsection{MSMEs Challenges}

This part summarizes the constraints of MSMEs' growth and sustainability using common variables in the literature. For comparison, we present the results using tables and econometric models. We asked respondents to identify MSMEs start-up constraints and growth challenge from the various options and rank them as sever, moderate and minor. The result is summarized below.

Table 22. MSEs' start-up constraints and growth challenges

\begin{tabular}{llll}
\hline Item No. & Constraints & Frequency & Percentage \\
\hline $\mathbf{1}$ & Lack of startup and working capital & 300 & 20.00 \\
\hline $\mathbf{2}$ & Unable to compete with large enterprises & 257 & 17.10 \\
$\mathbf{3}$ & Lack of market linkage and information access & 207 & 13.80 \\
$\mathbf{4}$ & Inadequate product/service demand & 170 & 11.30 \\
$\mathbf{5}$ & Inadequate working premises & 150 & 10.00 \\
$\mathbf{6}$ & Bureaucracy \& lack of follow up & 120 & 8.00 \\
$\mathbf{7}$ & Lack of BDS service \& skill-based training & 95 & 6.30 \\
$\mathbf{8}$ & Infrastructural problem & 65 & 4.30 \\
$\mathbf{9}$ & Insufficient technology & 50 & 3.30 \\
$\mathbf{1 0}$ & Inflation & 40 & 2.70 \\
$\mathbf{1 1}$ & An undeveloped image in the public & 33 & 2.20 \\
Total & & $\mathbf{1 4 8 7}$ & $\mathbf{1 0 0}$ \\
\hline
\end{tabular}

The MSMEs program faces many challenges that need to be surmounted in order to ensure smooth functioning and ensure sustainability. As seen from Table 22, the challenges mostly crop out from lack of startup and working capital, unable to compete with existing large firms, lack of market linkage and information access, inadequate product/or service demand and inadequate working premises are the top five ranked barriers to MSMEs growth and sustainability. 
In the focus group discussion with key informants and MSEs managers/owners, we identified the following limited product cost and quality, poor coordination between MSEs and other sectors, as other key challenges hampering MSMEs growth. It is important to think of all kinds of innovative mechanisms to ease these constraints. For example, in terms of finance, innovative mechanisms including private sector involvement and encouraging and exploring supplier credit, venture capital, mobilization of own and group finance, capital renting and so on.

\section{Conclusion and Recommendation}

\subsection{Status (Conclusions)}

Although MSMEs make the smallest total proportion of assets (17\%), their contribution to employment creation is much higher (99\%) than that of medium and large enterprises (1\%).

Despite their small size, Micro-enterprises make up about two-third enterprises. Thus, the smaller the enterprise, the larger the employment it creates, unlike two assets. Sector-wise, manufacturing and construction have built large assets $(10 \%)$ and more employment $(35 \%)$ as compared to petty trade, urban agriculture and service.

Notwithstanding some drawbacks cropping up from measurement and non-response errors of potentially essential income and output indicator variables; the contribution of micro-enterprises in terms of employment creation is higher as compared to small, medium and large enterprises. Sector-wise, construction and service sectors, most of which are relatively younger, are huge sponges absorbing many employees. Considering business ownership, cooperatives and sole proprietorship take the leading share in creating employment opportunities.

MSMEs are important means to empower women. Most of the surveyed female entrepreneurs reported that they have experienced significant empowerment in terms of access to resources, decision-making, gender perception, and overall living condition.

There has been a great increment in the construction (68\%), petty trade $(70 \%)$ and service sectors $(82 \%)$ which are not over three years old. In terms of actual numbers, construction is the highest (157) as compared to petty trade (130) and service (97) in the last three years.

Considering financial sources of MSEs, the two most important sources of finance during MSMEs start-up are personal saving and micro-finance.

MSMEs have a greater contribution of value added per person engaged. It is because of this the sector absorbs much labour force and it can be operational with low startup capital and skill. MSMEs play a significant role in poverty reduction.

In the log-linear regression, we found that MSMEs initial capital, BDS, access to credit facility are the key determinants of employment. We expect though females to account for about $50 \%$ of the entrepreneurs; they make up only one third (less involved in construction and manufacturing).

Regarding MSMEs linkages, there are weak institutional and sectoral linkages. Majority of the MSMEs produce for local and regional markets; few for national markets and none for international markets. In the logistic regression, we find it that sex of MSMEs owner/manager, BDS, access to credit and capital size strongly determine the survival of MSMEs.

\subsection{Prospects/Recommendations/}

$\{$ The policy for the growth of MSMEs is proper and needs to be further strengthening as it enhances employment and poverty reduction. Construction has the largest contribution to employment which can be further enhanced also by targeting the private sector.

$\$$ The findings of the study recommend woreda MSME offices and policymakers to focus on construction, service, and urban agriculture because of their contribution to a job opportunity. As young enterprises contribute more to the economy, we recommend it to always have young enterprises, i.e., the continuous establishment of MSEs in unexploited areas.

\& To enhance females' participation in MSMEs there should be an intervention, especially in the manufacturing and construction sectors.

\& In sample respondents, we learned that information flow is limited, and consumers and suppliers rarely meet. There is a dearth of knowledge about prices, products and supplies both on the buyers and sellers side. As a result, MSMEs will not know what the need and demanded and consumers will not know what kinds of 
products are available at what prices. Thus, innovative promotional mechanisms should be in place to overcome the problem.

\section{We should involve MSMEs in diversified sectors convenient for input-output linkages.}

Institutions should take MSMEs' development as their main targets, i.e., TVETs should identify profitable sectors; develop business plans; and organize their graduates and assign them in the specified areas. They should also closely follow-up implementing plans and adopt new technologies.

$\leqslant$ Universities (especially regional) should also consider MSMEs' development as a big pillar- capacity building of TVETs; research and outreach services on MSMEs should be also integrated as their strategic objectives.

$B$ Creating national and international market opportunities:

* Diversifying MSMEs in unexploited areas like honey production, incense, oil seeds, mining

* Creating linkages with big companies of the region e.g. MSMEs-ALTEX-cotton, Messobo and Saba Stones-Gypsum, Abergelle-live animals, MIE and so on.

As MSMEs are important means of livelihood and sources of women's empowerment, women entrepreneurs need special attention.

Universities, TVETs and research centres should gear up their research findings towards innovation by stimulating the development and spread of good practice in technology transfer, and in the nurturing of innovative enterprises.

3 It is better if the regional government tries to link MSMEs with each other and relevant bodies especially with TVETs and higher institutions (a linkage that promotes collaboration and competition at the same time).

3 We must create awareness so that MSMEs can inspire the habit of continuously training and developing their owners/managers and employees to build comprehensive capacity for maintaining their competitiveness.

B We should give technical and business training to MSMEs at a regular and well-organized way. The regional government should establish a well-organized and specialized training centre at least at regional and zonal levels. Hence, the training centres will be responsible to plan and execute need-based training. Particularly, a system of providing BDS including keeping a book of records during the stage of starting-up and during later phases of expansions.

We should exert efforts to change the perception/attitude of the community and youth. Especially attitudinal change and paradigm shift in saving habit and developing a clear vision.

Finally, it is highly recommended that the regional government in cooperation with development partners promote micro-enterprises in the region, as they are important sources of regional income; reduce inequality and using a significant number of persons. Besides, the regional government should continue its efforts to organize and help cooperatives. The support given to MSEs ought to be comprehensive ranging from providing start-up capital to introducing a better technology.

\section{References}

Aw, B. Y. (2001). Productivity Dynamics of Small and Medium Enterprises in Taiwan (China). The International Bank for Reconstruction and Development/the World Bank, Washington. https://doi.org/10.1007/978-1-4615-0963-9_5

Ayyagari, M., Demirguc-Kunt, A., \& Maksimovic, V. (2011). Small vs. Young Firms across the World Contribution to Employment, Job Creation, and Growth. The World Bank, Policy Research Working Paper 5631. https://doi.org/10.1596/1813-9450-5631

Eshetu, B., \& Zeleke, W. (2008). Factors that affect the long-term survival of Micro, Small and Medium Enterprises in Ethiopia. South African Journal of Economics, 76(3). https://doi.org/10.1111/j.1813-6982.2008.00207.x

Eshetu, B., \& Zeleke, W. (2008, November). Women Entrepreneurship in Micro, Small and Medium Enterprises: The Case of Ethiopia. Journal of International Women's Studies, 10(2).

Gebrehiwot, A., \& Wolday, A. (2006). Micro and Small Enterprises (MSEs) Finance in Ethiopia: Empirical Evidence. Eastern Africa Social Science Research Review, 22(1), 63-86. https://doi.org/10.1353/eas.2006.0002 
Green, C. J., Kirkpatrick, C. H., \& Murinde, V. (2006). Finance for Small Enterprise Growth and Poverty Reduction in Developing Countries. Journal of International Development, 18, 1017-1030. https://doi.org/10.1002/jid.1334

Haftu Berihun, et al. (2009). Financial Needs of Micro and Small Enterprise (MSE) Operators in Ethiopia. Occasional Paper No. 24, AEMFI, Addis Ababa.

ILO. (2003). Ethiopian Women Entrepreneurs: Going for Growth. Jobs Gender and Small Enterprises in Africa.

Marcucci, P. N. (2001). Jobs, gender and small enterprises in Africa and Asia: Lessons are drawn from Bangladesh, the Philippines, Tunisia and Zimbabwe. Series on Women's Entrepreneurship Development and Gender in Enterprises-WEDGE, International Labor Office, Geneva.

McClelland, S. D. (2002). A Training Needs Assessment for the United Way of Dunn County Wisconsin. Unpublished MSc Thesis, University of Wisconsin-Stout.

McPherson, M. A. (1999). Micro and Small-Scale Enterprises in Zimbabwe: Results of a Country-Wide Survey. Michigan State University.

Mead, D. C., \& Liedholm, C. (1998). The dynamics of micro and small enterprises in developing countries. World Development, 26(1), 61-74. https://doi.org/10.1016/S0305-750X(97)10010-9

Nichter, S., \& Goldmark, L. (2005). Understanding Micro and Small Enterprise Growth. USAID, Development Alternatives, Inc. microREPORT \#36.

Nichter, S., \& Goldmark, L. (2009). Small Firm Growth in Developing Countries. World Development, 37(9), 1453-1464. https://doi.org/10.1016/j.worlddev.2009.01.013

Organization for Economic Co-operation and Development, OECD. (2002). High-Growth SMEs and Employment.

Rahel, W., \& Issac, P. (2010). Growth Determinants of Women-Operated Micro and Small Enterprises in Addis Ababa. Journal of Sustainable Development in Africa, 12(6).

Schorling, A. (2006). The Involvement of Women and Men in Micro \& Small Enterprises (MSEs) in Nefas Silk Lafto Sub City: Discussion Paper \& Guideline to Construct a Gender-Sensitive "Job Market". Addis Ababa.

Seleshi Lemma. (2001). Subcontracting Strategy for the Ethiopian Micro and Small Enterprises.

Small and Medium Enterprise Development Authority of Pakistan (SMEDAP). (2002). Creating a conducive policy environment for micro, small and medium-sized enterprises in Pakistan. SEED working paper number 29. Geneva: International Labour Office.

Solomon, D. (2002). The Establishment of Network of Micro and Small Enterprise Support Institutions in TigraY GTZ-MSE Programme.

The trade and Industry Bureau Addis Ababa. (June 2005). The working definition of MSE in Ethiopia-based on capital.

Uzor, O. (2004). Small and Medium-Scale Enterprises Cluster Development in the South-Eastern Region of Nigeria. Institute for World Economics and International Management, Universität Bremen.

Weldeslassie, H. A. (2017). Does microfinance help to reduce poverty in Ethiopia? Propensity score matching impact analysis. Enterprise Development and Microfinance, 28(4), 255-283. https://doi.org/10.3362/1755-1986.2017.HAW

Woldelul, A. (2004). Marketing Strategies: For Micro and Small Enterprises in Ethiopia. Ethiopian Business Development Services Network, Addis Ababa, Ethiopia.

Zewde \& Associates. (2002). Jobs, Gender and Small Enterprises in Africa: Women Entrepreneurs in Ethiopia. Preliminary Report, SEED-ILO Addis Ababa. 


\section{Appendix}

Annex-1 Population and Sample Size

\begin{tabular}{|c|c|c|c|c|c|c|c|c|c|c|c|c|c|c|}
\hline \multirow[t]{2}{*}{ № } & \multirow[t]{2}{*}{ Sample City } & \multicolumn{4}{|c|}{$\begin{array}{c}\text { Sector } \\
\text { (Total Population) }\end{array}$} & \multirow[t]{2}{*}{ Total Population } & \multicolumn{7}{|c|}{$\begin{array}{l}\text { Sector } \\
\text { (Sample Size ) }\end{array}$} & \multirow[t]{2}{*}{$\begin{array}{l}\text { Sample } \\
\text { Size }\end{array}$} \\
\hline & & S1 & S2 & S3 & S4 & & S1 & S2 & $\mathbf{S 3}$ & S4 & S5 & S6 & S7 & \\
\hline 1 & Mekelle & 2444 & 1547 & 2100 & 12798 & 18889 & 132 & 82 & 70 & 109 & 42 & 9 & 2 & 446 \\
\hline 2 & Wukro & 156 & 140 & 524 & 3132 & 3952 & 17 & 20 & 14 & 9 & 32 & 2 & 2 & 96 \\
\hline 3 & Adigrat & 209 & 176 & 404 & 3923 & 4712 & 17 & 15 & 28 & 18 & 13 & 14 & 1 & 106 \\
\hline 4 & Freweini & 0 & 15 & 89 & 841 & 945 & 6 & 1 & 6 & 2 & 5 & 6 & 0 & 22 \\
\hline 5 & Enticho & 83 & 71 & 111 & 1460 & 1725 & 14 & 4 & 7 & 4 & 9 & 3 & 0 & 41 \\
\hline 6 & Adwa & 34 & 183 & 335 & 2886 & 3438 & 4 & 7 & 13 & 34 & 14 & 9 & 1 & 82 \\
\hline 7 & Aksum & 490 & 260 & 491 & 7153 & 8394 & 26 & 19 & 34 & 68 & 17 & 25 & 6 & 195 \\
\hline 8 & Shire & 522 & 288 & 728 & 5122 & 6660 & 12 & 9 & 29 & 58 & 19 & 30 & 1 & 158 \\
\hline 9 & Sheraro & 18 & 38 & 130 & 1573 & 1759 & 1 & 2 & 2 & 18 & 17 & 0 & 0 & 40 \\
\hline 10 & Humera & 17 & 95 & 524 & 1884 & 2520 & 4 & 9 & 19 & 13 & 14 & 0 & 1 & 60 \\
\hline 11 & Dansha & 0 & 1 & 33 & 216 & 250 & 0 & 0 & 1 & 3 & 2 & 0 & 0 & 6 \\
\hline 12 & Abi-adi & 211 & 99 & 103 & 1351 & 1764 & 20 & 6 & 3 & 8 & 11 & 0 & 0 & 48 \\
\hline 13 & Adi-gudom & 17 & 17 & 71 & 667 & 772 & 6 & 7 & 3 & 13 & 1 & 1 & 0 & 31 \\
\hline 14 & Maychew & 54 & 41 & 182 & 1529 & 1806 & 3 & 1 & 3 & 22 & 8 & 6 & 0 & 43 \\
\hline 15 & Korem & 93 & 53 & 145 & 1296 & 1587 & 2 & 3 & 2 & 20 & 5 & 3 & 0 & 35 \\
\hline 16 & Mekoni & 96 & 23 & 114 & 688 & 921 & 2 & 1 & 1 & 9 & 6 & 2 & 0 & 21 \\
\hline 17 & Alamata & 136 & 64 & 295 & 2552 & 3047 & 4 & 4 & 7 & 44 & 7 & 4 & 0 & 70 \\
\hline \multicolumn{2}{|c|}{ Total } & & & & & 63,141 & 270 & 190 & 249 & 445 & 222 & 110 & 14 & 1500 \\
\hline
\end{tabular}

Source of population: Tigrai Trade and Industry Bureau

\section{Key (for annex-1)}

$\mathrm{S} 1=$ Construction

$\mathrm{S} 2=$ Metal and woodwork

S3 $=$ Services

S4=Petty trade

S5 $=$ Urban agriculture

S6= Textile

S7 $=$ Handicraft

\section{Copyrights}

Copyright for this article is retained by the author(s), with first publication rights granted to the journal.

This is an open-access article distributed under the terms and conditions of the Creative Commons Attribution license (http://creativecommons.org/licenses/by/4.0/). 